\title{
Parallel solution synthesis of lavendustin analogs as antileishmanial agents
}

\author{
Diego G. Ghiano, ${ }^{\text {a }}$ Paulo B. Carvalho, ${ }^{\mathrm{b}}$ Babu L. Tekwani, ${ }^{\mathrm{c}}$ Mitchell A. Avery, \\ and Guillermo Labadie ${ }^{\mathrm{a} *}$ \\ ${ }^{a}$ IQUIR (Instituto de Química Rosario), CONICET- UNR, Suipacha 531, S2002LRK, Rosario, \\ Argentina \\ ${ }^{b}$ Schoool of Pharmacy, College of Notre Dame of Maryland, Baltimore, Maryland, 21210, USA \\ ${ }^{c}$ National Center for Natural Products Research \& Department of Pharmacology, University of \\ Mississippi, University, MS 38677, USA \\ ${ }^{d}$ Department of Medicinal Chemistry, School of Pharmacy, University of Mississippi, University, \\ MS 38677, USA \\ E-mail:labadie@iquir-conicet.gov.ar
}

\section{Dedicated to Dr. Manuel Gonzalez Sierra on the occasion of his 65th birthday}

\begin{abstract}
A concise parallel synthesis of 12 lavendustin analogs is described. Starting with differently substituted benzaldehydes, a two-step sequence involving reductive amination and $\mathrm{N}$-benzylation accelerated by microwaves was performed to provide the compounds in excellent yields. The compounds have been assayed in vitro showing activity against Leishmania donovani, the causative agent of visceral leishmaniasis.
\end{abstract}

Keywords: Benzylamines, reductive amination, microwave, leishmaniasis

\section{Introduction}

Leishmaniasis is a parasitic disease caused by protozoan haemoflagellates of the genus Leishmania, which has more than 30 known species, with 20 of those species being pathogenic towards humans. ${ }^{1}$ There are three main forms of the disease: cutaneous, muco-cutaneous and visceral, the latter being the most severe form, fatal in almost $100 \%$ of the cases if left untreated. Visceral leishmaniasis (VL) has major public health implications in the Indian subcontinent (Bangladesh, India and Nepal), East Africa (Ethiopia, Kenya and Sudan) and Latin America (Brazil). It has been estimated that this diseases has 500,000 cases per annum and affects mostly the poorest and most marginalized communities living in primarily rural areas. Of the annual 
cases, $60 \%$ occur in about 109 districts of India, Bangladesh and Nepal, where about 150 million people are at risk of developing VL. ${ }^{2}$ Visceral leishmaniasis is primarily caused by Leishmania donovani and affects the spleen, liver, lymph nodes and bone marrow.

Pentavalent antimonial compounds, sodium stibogluconate (Pentosam) and meglumine antimoniate (Glucantime) have been used for many decades as the main choice in antileishmanial chemotherapy. ${ }^{3}$ Some drawbacks associated with these drugs are their high toxicities, variable efficacy, intravenous administration in high dosages and an increasing number of reports of drug resistance, especially in endemic areas. ${ }^{4}$
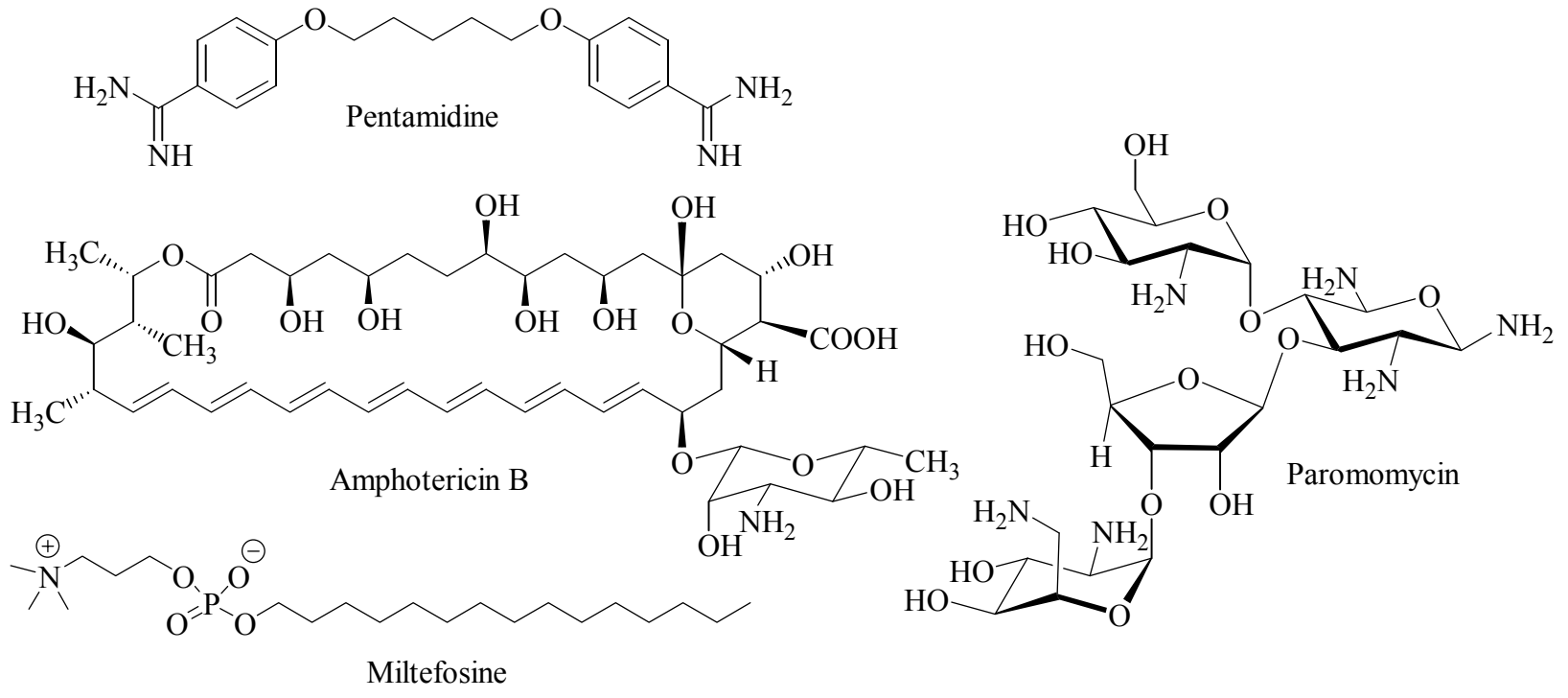

Figure 1. Antileishmanial drugs.

Recently, Pentamidine and Amphotericin B has been added as alternative drugs but, for different reasons, i.e. high prices and undesirable side effects and difficult availability, are limited. ${ }^{5}$ Miltefosine, a new drug for the treatment of visceral leishmaniasis went to Phase IV trials in public and private clinics in India few years ago, ${ }^{6}$ and has been recommended for visceral disease in India and in Ethiopia, and for the cutaneous form of the disease in Colombia and Bolivia. ${ }^{7}$ Paromomycin, was originally isolated from Streptomyces krestomuceticus in the 1950s, and studied as an antibiotic. This compound has recently passed a multi-center phase III study in India, demonstrating high efficacy, affordability, and presenting itself as a safe treatment. ${ }^{8}$ These results prompted the Drug Controller General of India (DCGI) to approve paromomycin for the treatment of visceral leishmaniasis. ${ }^{9}$ Despite the encouraging success obtained thus far, there is a long way to go yet in order to find new and improved drug candidates, to add to the arsenal of oral chemotherapeutics against leishmaniasis and other neglected parasitic diseases. ${ }^{10}$

During the last few years, different compounds against several forms of leishmaniasis have been isolated from natural sources or have been designed, synthesized and tested, - i.e. the 
anticancer tamoxifen, ${ }^{11}$ chalcones, ${ }^{12}$ bisphosphonates, ${ }^{13}$ and polyamines ${ }^{14}$ and also many pentamidine analogs. ${ }^{15}$

Tubulin is a globular protein that assembles into microtubules in vivo and in vitro under the proper conditions. Microtubules play critical roles in mitosis, the maintenance of cell shape, cell motility, and organelle transport in eukaryotes. It has been postulated that different compounds have tubulin as a target, including drugs to treat cancer, fungal and helminthal infections. Among those compounds are anthelmintic benzimidazols, like oxfendazole and thiabendazole, and also some herbicidal dinitroanilines such as trifluralin and oryzalin. All of these have shown to possess a phylogenetic selectivity for tubulin. Werbovetz and collaborators, based on those precedents, have proposed and validated that tubulin can also be a target to design new antileishmanial agents. ${ }^{16}$ Over the last ten years an extensive work has been conducted preparing different libraries of antitubulin herbicidal analogs generating a group of promising drug candidates for antileishmanial chemotherapy. ${ }^{17}$

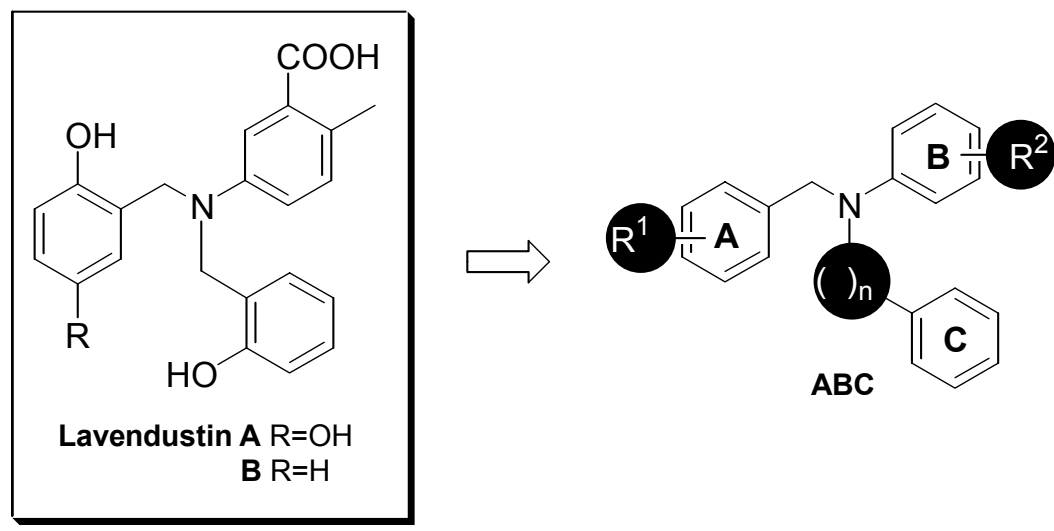

Figure 2. Lavendustins $\mathbf{A}$ and $\mathbf{B}$, and general structure of the designed analogs.

Lavendustin A is a natural metabolite that was first isolated by Onoda from Streptomyces griseolavendus in 1989. The initial reported activity of Lavendustin was protein-tyrosine kinase inhibition, but later this compound and its synthetic partial structure have been validated as tubulin polymerization inhibitors. ${ }^{18}$

As previously stated, tubulin is a validated target for the design of antileishmanial drugs and lavendustin is an inhibitor of tubulin polymerization, we envisioned that this natural product would be a privileged scaffold to design new synthetic analogs with potential activity against leishmaniasis.

Based on the structure of lavendustin, a series of analogs $\mathbf{A B C}$ were proposed (Figure 2). The analogs preserve the benzyl and aniline moieties, respectively named rings $\mathbf{A}$ and $\mathbf{B}$. We chose to introduce diversity through substitutions on aromatic rings $\mathbf{A}$ and $\mathbf{B}$ and the number of methylenes groups between ring $\mathbf{C}$ and the central nitrogen. 
As part of our program to design and synthesize new agents against parasitic diseases, we describe herein the synthesis of a series of $12 \mathrm{~N}, \mathrm{~N}$-disubstituted anilines and their activities against Leishmania donovani promastigotes.

\section{Synthesis}

Based on the general ABC structure, a series of 12 compounds was prepared through 6 common intermediates. A concise synthetic strategy was designed that starts with a reductive amination of the benzaldehydes and the aniline completing the synthesis with the $N$-alkylation of the secondary amine intermediate. The substituents chosen for rings A and B were benzyloxy and methoxyl groups, in order to prevent oxidative degradation and to simplify the synthesis.

Commercial benzaldehydes and anilines were mixed with $\mathrm{NaBH}(\mathrm{OAc})_{3}$ and $\mathrm{AcOH}$ in dichloromethane ${ }^{19}$ to produce 6 different substituted anilines. After purification, the necessary intermediates were obtained in $89 \%$ average yield (Scheme 1).

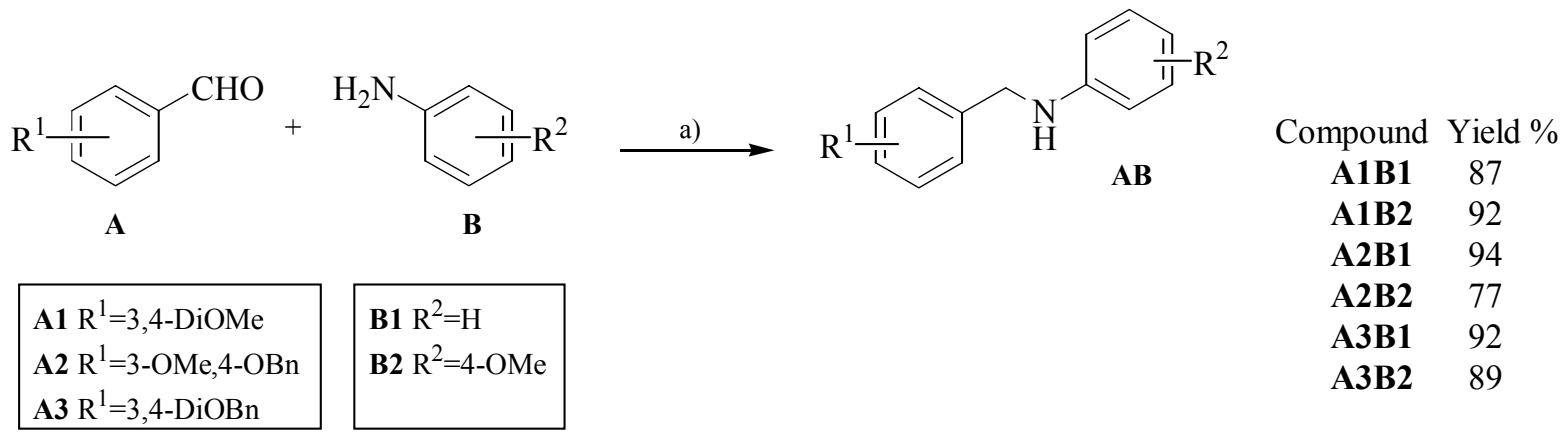

a) $\mathrm{NaBH}(\mathrm{AcO})_{3}, \mathrm{AcOH}, \mathrm{DCM}$, room temp, overnight.

Scheme 1. Reductive amination of substituted aldehydes A.

The last step involved an N-alkylation of the secondary amines AB. This reaction usually works efficiently with several soft nucleophiles. On the other hand, for some nitrogen-containing nucleophiles like aniline derivatives, the benzylation can be extremely slow (1-4 days) even at an elevated temperature. Initially, standard conditions were used, where the amines $\mathbf{A B}$ were treated with benzyl bromide in DMF using potassium carbonate as base at $100{ }^{\circ} \mathrm{C}$ for 18 hours. Under those conditions, it was observed that reaction mixture contained degradation products, while obtaining the expected tertiary amine ABC after purification only in moderate yields. To improve the yield and decrease reaction time, a microwave accelerated reaction was tested. This reaction was initially conducted under microwave irradiation using the same solvent and base that were used under normal heating, producing the expected acceleration of the reaction, decreasing the reaction time from 18 hours to 10-30 minutes, depending of the substrate. After that, the solvent was also studied considering the microwave energy to heat transferability according to the loss angle ( $\tan \delta$ ). ${ }^{20}$ Reactions using different solvents were tested (DMF, THF and toluene), being acetonitrile the one which performed better. With these conditions in hand, 
the $6 \mathrm{~N}$-substituted anilines were alkylated using benzyl bromide and 2-bromoethyl benzene (phenethyl bromide), using potassium carbonate as base in acetonitrile. The purified 12 lavendustin analogs were obtained with an $85 \%$ average yield. (Table 1).

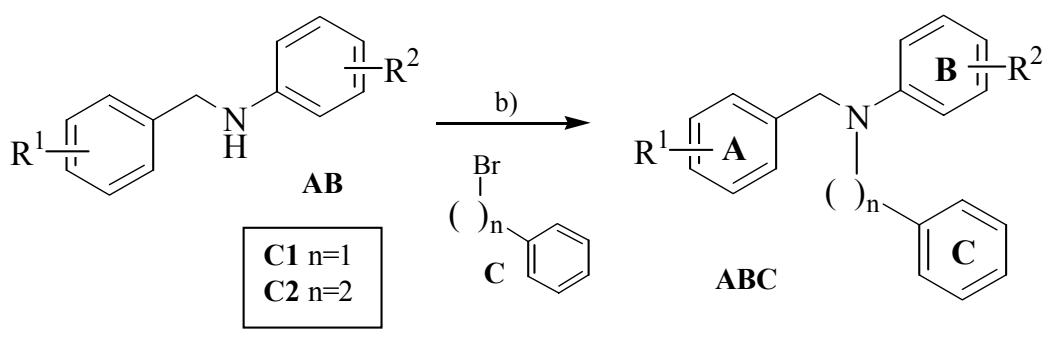

b) $\mathrm{K}_{2} \mathrm{CO}_{3}, \mathrm{Br}-\mathrm{R}, \mathrm{MeCN}$, mw

Scheme 2. N-Alkylation of secondary amine intermediates AB.

\section{Biological activity}

The lavendustin analogs $\mathbf{A B C}$ were tested in vitro against Leishmania donovani promastigotes. The activities of the compounds are shown on Table 1. As shown, most of the compounds were active with the exception of A1B1C2 and A3B1C1 (the maximum concentration tested was 40 $\mu \mathrm{g} / \mathrm{mL}$ ). The range of activity for the remaining ten compounds was narrow, being $6.5 \mu \mathrm{g} / \mathrm{mL}$ the most active, and $40 \mu \mathrm{g} / \mathrm{mL}$ the less active. The activity (determined as $\mathrm{IC}_{50}$ ) of the most active compound A1B1C1 was $6.5 \mu \mathrm{g} / \mathrm{mL}$ when for the control antileishmanial drugs pentamidine was and $1.7 \mu \mathrm{g} / \mathrm{mL}$, and for Amphotericine B was $0.15 \mu \mathrm{g} / \mathrm{mL}$.

Table 1. Antileishmanial activity of $\mathrm{ABC}$ products

\begin{tabular}{cccc}
\hline & & N-benzylation & L. donovani \\
\cline { 3 - 4 } Compound & $\mathrm{n}$ & Yield \% & $\mathrm{IC}_{50} \mu \mathrm{g} / \mathrm{mL}$ \\
\hline A1B1C1 & 1 & 91 & 6.5 \\
A1B1C2 & 2 & 87 & $\mathrm{NA}$ \\
A1B2C1 & 1 & 90 & 20 \\
A1B2C2 & 2 & 91 & 26 \\
A2B1C1 & 1 & 81 & 26 \\
A2B1C2 & 2 & 88 & 20 \\
A2B2C1 & 1 & 84 & 16 \\
A2B2C2 & 2 & 86 & 26 \\
A3B1C1 & 1 & 83 & $\mathrm{NA}$ \\
A3B1C2 & 2 & 87 & 40 \\
A3B2C1 & 1 & 78 & 35 \\
A3B2C2 & 2 & 77 & 26 \\
Amphotericin B & & & 0.15 \\
Pentamidine & & & 1.7 \\
\hline
\end{tabular}

$\mathrm{NA}=$ non active. 
Since antitubulin compounds have also shown promising activity against different apicomplexan parasites including the causative agent of malaria, ${ }^{21}$ we decided to test the antimalarial activity of the compounds prepared against two different strains of Plasmodium falciparum, one sensitive and another resistant to chloroquine. (D6, Sierra Leone, sensitive; W2, IndoChina, resistant). Unfortunately none of the compounds showed activity below $4.75 \mu \mathrm{g} / \mathrm{mL}$, a value considered inactive compared to the control drugs artemisinin $\left(\mathrm{IC}_{50}=5.3 \mathrm{ng} / \mathrm{mL}\right.$ for D6, $\mathrm{IC}_{50}=4.9 \mathrm{ng} / \mathrm{mL}$ for W2) and chloroquine $\left(\mathrm{IC}_{50}=9.5 \mathrm{ng} / \mathrm{mL}\right.$ for $\mathrm{D} 6, \mathrm{IC}_{50}=148,5 \mathrm{ng} / \mathrm{mL}$ for W2). The cytotoxicity test toward Vero cells revealed that all the compounds were non-cytotoxic at $4.75 \mu \mathrm{g} / \mathrm{mL}$.

A more detailed analysis of the activity of these compounds can be done by grouping into families according to the building block $\mathbf{C}$. (Table 2) In the $\mathbf{C 1}$ family, when the B1 derivatives are analyzed, it is clear that increasing the size of the phenol substituents decreased the activity. In the $\mathbf{B} 2$ group, this behavior is not observed, having a similar $\mathrm{IC}_{50}$ on average. Moving to the C2 family, similar structural-activity was observed, with activities for B1 analogs that decrease from $\mathbf{A} 1$ to $\mathbf{A} 3$ with $\mathbf{B 2}$ analogs with same $\mathrm{IC}_{50}$ values no matter the phenol subtituent. The only exception is A1B1C2 that was surprisingly inactive. In general terms, the introduction of a second methylene on the $\mathbf{C}$ building block had no effect on the antileishmanial activity, not producing any substantial change on the activities besides the effect on A1B1. In summary, the best activity was observed with dimethoxy substitution on the A ring, no oxygenated subtituent on the $\mathbf{B}$ ring and N-Benzyl group for the ring $\mathbf{C}$.

Table 2. Antileishmanial activity* ordered by families

\begin{tabular}{cccccccc}
\hline C1 & & B1 & B2 & C2 & & B1 & B2 \\
\hline & $\mathbf{R}^{\mathbf{1}} \backslash \mathbf{R}^{\mathbf{2}}$ & $\mathrm{H}$ & $\mathrm{OMe}$ & & $\mathbf{R}^{\mathbf{1}} \backslash \mathbf{R}^{\mathbf{2}}$ & $\mathrm{H}$ & $\mathrm{OMe}$ \\
$\mathbf{A 1}$ & DiMeO & 6.5 & 20 & $\mathbf{A 1}$ & $\mathrm{DiMeO}$ & $\mathrm{NA}$ & 26 \\
$\mathbf{A 2}$ & $\mathrm{MeO}, \mathrm{BnO}$ & 20 & 16 & $\mathbf{A 2}$ & $\mathrm{MeO}, \mathrm{BnO}$ & 20 & 26 \\
$\mathbf{A 3}$ & DiBnO & NA & 35 & $\mathbf{A 3}$ & $\mathrm{DiBnO}$ & 40 & 26 \\
\hline
\end{tabular}

*The values given are $\mathrm{IC}_{50}(\mu \mathrm{g} / \mathrm{ml})$.

\section{Conclusions}

A straightforward synthetic route was used to prepare a small collection of compounds introducing a microwave accelerated $N$-alkylation in very good yields. The antileishmanial activity of this family of 12 lavendustin analogs clearly validated this natural product as a valuable scaffold to prepare new antileishmanial drugs. Further studies will include the preparation of new collections of analogs with halogenated and non-polar substituents on the $\mathbf{B}$ ring and different patterns of dimethoxy substitution on the A ring. 


\section{Experimental Section}

General. ${ }^{1} \mathrm{H}$ and ${ }^{13} \mathrm{C}$ NMR spectra were measured on a $400 \mathrm{MHz}$ Bruker Avance DRX or a 300 $\mathrm{MHz}$ Bruker Avance II using $\mathrm{CDCl}_{3}$ as solvent. Chemical shifts were reported in ppm downfield from tetramethylsilane $(\delta)$ as the internal standard and coupling constants are in hertz $(\mathrm{Hz})$. Assignments of proton resonances were confirmed by correlated spectroscopy (HH COSY and Heteronuclear Single Quantum Coherence, HSQC) high-resolution mass spectra (HRMS) were recorded on a Micromass spectrometer with lock spray source or Bruker MicroTOF II. Microwave accelerated reactions were performed in a CEM discovery microwave reactor. All the melting points were determined in open Pyrex capillaries with a Electrothermal 9000 melting point apparatus and are uncorrected. The reaction progress was monitored on precoated silica gel G or GP TLC plates. Spots were visualized under $254 \mathrm{~nm}$ UV light and/or by dipping the TLC plate into a solution of $2 \mathrm{~mL}$ anisaldehyde and $10 \mathrm{~mL}$ glacial acetic acid and $5 \mathrm{~mL} \mathrm{H}_{2} \mathrm{SO}_{4}$ in 340 $\mathrm{mL} \mathrm{MeOH}$ followed by heating with a heat gun. Column chromatography was performed with silica gel 60 (230-400 mesh) under a low pressure of nitrogen, using increasing EtOAc-hexane gradients as solvent. All the solvents (hexane, ethyl acetate, $\mathrm{CH}_{2} \mathrm{Cl}_{2}, \mathrm{Et}_{2} \mathrm{O}$ ) were distilled prior to use. All reactions were performed under an atmosphere of nitrogen or argon using oven-dried glassware and standard syringe/septa techniques. $\mathrm{CH}_{2} \mathrm{Cl}_{2}$ was dried over $\mathrm{P}_{2} \mathrm{O}_{5}$. DMF was distilled from $\mathrm{BaO}$.

\section{General procedure for reductive amination}

To a solution of aldehyde (1.0 equiv) in $10 \mathrm{~mL}$ of dichloromethane, amine (1.1 equiv), $\mathrm{NaBH}(\mathrm{AcO})_{3}$ (1.4 equiv) and finally acetic acid (1.1 equiv) were added in this order and the reaction mixture was stirred overnight at room temperature. Then, the reaction was quenched by addition of $5 \% \mathrm{NaHCO}_{3}(30 \mathrm{~mL})$ and the layers were separated and the aqueous phase was extracted with ether $(4 \times 10 \mathrm{~mL})$. Combined organic extracts were dried over $\mathrm{Na}_{2} \mathrm{SO}_{4}$ and concentrated. The products were purified by column chromatography.

$N$-(3,4-Dimethoxybenzyl)aniline (A1B1). 3,4-dimethoxybenzaldehyde (104 mg, $0.63 \mathrm{mmol}$ ); aniline $(63 \mu \mathrm{L}, 0.69 \mathrm{mmol})$ in dry dichloromethane $(6 \mathrm{~mL})$; sodium triacetoxyborohydride (204 $\mathrm{mg}, 0.96 \mathrm{mmol})$ and acetic acid $(64 \mu \mathrm{L})$. Purification by column chromatography provides 133 $\mathrm{mg}(87 \%)$ of the amine A1B1 as yellowish oil. ${ }^{1} \mathrm{H}$ NMR (400 $\left.\mathrm{MHz} \mathrm{CDCl}_{3}\right): 7.25-7.21(\mathrm{~m}, 2 \mathrm{H})$, 6.97-6.68 (m, 6H), $4.29\left(\mathrm{~s}, 2 \mathrm{H}, \mathrm{C}_{\mathrm{Al} 1}-\mathrm{CH}_{2}\right), 3.91\left(\mathrm{~s}, 3 \mathrm{H}, \mathrm{C}_{\mathrm{A} 4}-\mathrm{OMe}\right), 3.90\left(\mathrm{~s}, 3 \mathrm{H}, \mathrm{C}_{\mathrm{A} 3}-\mathrm{OMe}\right) .{ }^{13} \mathrm{C}$ NMR (100 MHz CDCl $)$ : $149.3\left(\mathrm{C}_{\mathrm{B} 1}, \mathrm{C}\right), 148.3\left(\mathrm{C}_{\mathrm{A} 3}-\mathrm{C}_{\mathrm{A} 4}, \mathrm{C}\right), 132.1\left(\mathrm{C}_{\mathrm{A} 1}, \mathrm{C}\right), 129.3\left(\mathrm{C}_{\mathrm{B} 2}-\mathrm{C}_{\mathrm{B} 6}\right.$, C), $119.7\left(\mathrm{C}_{\mathrm{A} 6}, \mathrm{CH}\right), 117.6\left(\mathrm{C}_{\mathrm{B} 4}, \mathrm{CH}\right), 112.9\left(\mathrm{C}_{\mathrm{B} 2}-\mathrm{C}_{\mathrm{B} 6}, \mathrm{CH}\right), 111.4\left(\mathrm{C}_{\mathrm{A} 5}, \mathrm{CH}\right), 110.9\left(\mathrm{C}_{\mathrm{A} 2}, \mathrm{CH}\right)$, 56.0 and $55.9\left(\mathrm{C}_{\mathrm{A}^{3}} \mathrm{OMe}, \mathrm{C}_{\mathrm{A}^{-}}-\mathrm{OMe}\right), 48.3\left(\mathrm{C}_{\mathrm{A}^{-}}-\underline{\mathrm{CH}_{2}}\right)$. ESI-HRMS Calcd for $\left(\mathrm{M}+\mathrm{Na}^{+}\right)$ $\mathrm{C}_{15} \mathrm{H}_{17} \mathrm{NO}_{2} \mathrm{Na}$ : 266.1157, found: 266.1147 .

$\mathrm{N}$-(3,4-Dimethoxybenzyl)-4-methoxyaniline (A1B2). 3,4-dimethoxybenzaldehyde (110 mg, $0.66 \mathrm{mmol})$; p-anisidine $(90 \mathrm{mg}, 0.73 \mathrm{mmol})$ in dry dichloromethane $(6.5 \mathrm{~mL})$; sodium triacetoxyborohydride $(216 \mathrm{mg}, 1.02 \mathrm{mmol})$ and acetic acid $(67 \mu \mathrm{L})$. Purification by column chromatography provides $166 \mathrm{mg}$ (92\%) of the amine A1B2 as white crystalline solid. Mp 114- 
$116{ }^{\circ} \mathrm{C} .{ }^{1} \mathrm{H}$ NMR $\left(400 \mathrm{MHz} \mathrm{CDCl}_{3}\right): 6.95-6.80$ (m, 4H, aromatic), 6.65-6.63 (m, 3H, , aromatic), $4.23\left(\mathrm{~s}, 2 \mathrm{H}, \mathrm{C}_{\mathrm{Al}}-\underline{\mathrm{CH}}_{2}\right), 3.89$ (s, 3H, $\left.\mathrm{C}_{\mathrm{A} 3}-\mathrm{OMe}\right), 3.88$ (s, 3H, $\left.\mathrm{C}_{\mathrm{A} 4}-\mathrm{OMe}\right), 3.76$ (s, 3H C $\left.\mathrm{C} 4-\mathrm{OMe}\right)$. ${ }^{13} \mathrm{C}$ NMR (100 MHz CDCl 3$): 152.1\left(\mathrm{C}_{\mathrm{B} 4}, \mathrm{C}\right), 149.0\left(\mathrm{C}_{\mathrm{A} 3}, \mathrm{C}\right), 148.1\left(\mathrm{C}_{\mathrm{A} 4}, \mathrm{C}\right), 142.4\left(\mathrm{C}_{\mathrm{B} 1}, \mathrm{C}\right)$, $132.2\left(\mathrm{C}_{\mathrm{A} 1}, \mathrm{C}\right), 119.5\left(\mathrm{C}_{\mathrm{A} 6}, \mathrm{CH}\right), 114.8\left(\mathrm{C}_{\mathrm{B} 2}-\mathrm{C}_{\mathrm{B} 6}, \mathrm{CH}\right), 114.0\left(\mathrm{C}_{\mathrm{B} 3}-\mathrm{C}_{\mathrm{B} 5}, \mathrm{CH}\right), 111.2\left(\mathrm{C}_{\mathrm{A} 2}, \mathrm{CH}\right)$, $110.8\left(\mathrm{C}_{\mathrm{A} 5}, \mathrm{CH}\right), 55.8\left(\mathrm{C}_{\mathrm{B} 4}-\mathrm{OMe}\right), 55.7\left(\mathrm{C}_{\mathrm{A} 4}-\mathrm{OMe}\right), 55.6\left(\mathrm{C}_{\mathrm{A} 3}-\mathrm{OMe}\right), 49.0\left(\mathrm{C}_{\mathrm{A} 1}-\underline{\mathrm{CH}}_{2}\right)$. ESIHRMS Calcd for $\left(\mathrm{M}+\mathrm{Na}^{+}\right) \mathrm{C}_{16} \mathrm{H}_{19} \mathrm{NO}_{3} \mathrm{Na}: 296.1250$, found: 296.1263 .

$\mathrm{N}$-(4-(Benzyloxy)-3-methoxybenzyl)aniline (A2B1). 4-benzyloxy-3-methoxybenzaldehyde (108 mg, $0.45 \mathrm{mmol})$; aniline $(45 \mu \mathrm{L}, 0.49 \mathrm{mmol})$ in dry dichloromethane $(4 \mathrm{~mL})$; sodium triacetoxyborohydride $(145 \mathrm{mg}, 0.69 \mathrm{mmol})$ and acetic acid $(45 \mu \mathrm{L})$. Purification by column chromatography provides $134 \mathrm{mg}(94 \%)$ of the amine A2B1 as a yellow solid. Mp 76-77 ${ }^{\circ} \mathrm{C} .{ }^{1} \mathrm{H}$ NMR (400 MHz $\left.\mathrm{CDCl}_{3}\right)$ : 7.53-7.25 (m, 7H, aromatic), 7.04-6.69 (m, 6H, aromatic), 5.20 (s, $2 \mathrm{H}$, $\left.\mathrm{C}_{\mathrm{A} 4}-\mathrm{OCH}_{2} \mathrm{Ph}\right), 4.27$ (s, $\left.2 \mathrm{H}, \mathrm{C}_{\mathrm{A} 4}-\mathrm{OCH}_{2}\right), 3.95$ (s, 3H, $\left.\mathrm{C}_{\mathrm{A} 3}-\mathrm{OMe}\right) .{ }^{13} \mathrm{C} \mathrm{NMR}\left(100 \mathrm{MHz} \mathrm{CDCl}_{3}\right)$ : $148.8\left(\mathrm{C}_{\mathrm{B} 1}, \mathrm{C}\right), 148.2\left(\mathrm{C}_{\mathrm{A} 4}, \mathrm{C}\right), 148.1\left(\mathrm{C}_{\mathrm{A} 3}, \mathrm{C}\right), 136.9\left(\mathrm{C}_{\mathrm{A} 1}, \mathrm{C}\right), 131.9\left(\mathrm{OCH}_{2} \underline{\mathrm{Ph}}\right), 129.1\left(\mathrm{OCH}_{2} \underline{\mathrm{Ph}}\right)$, $128.4\left(\mathrm{OCH}_{2} \underline{\mathrm{Ph}}\right), 127.7\left(\mathrm{OCH}_{2} \underline{\mathrm{Ph}}\right), 127.3\left(\mathrm{C}_{\mathrm{B} 3}-\mathrm{C}_{\mathrm{B} 5}, \mathrm{CH}\right), 120.2\left(\mathrm{C}_{\mathrm{A} 6}, \mathrm{CH}\right), 117.4\left(\mathrm{C}_{\mathrm{B} 4}, \mathrm{CH}\right)$, 113.6 ( $\left.\mathrm{C}_{\mathrm{A} 2}, \mathrm{CH}\right), 112.7\left(\mathrm{C}_{\mathrm{B} 2}-\mathrm{C}_{\mathrm{B} 6}, \mathrm{CH}\right), 111.9\left(\mathrm{C}_{\mathrm{A} 5}, \mathrm{CH}\right), 70.9\left(\mathrm{C}_{\mathrm{A} 4}-\mathrm{OCH}_{2} \mathrm{Ph}\right), 55.9\left(\mathrm{C}_{\mathrm{A} 3}-\mathrm{OCH}_{3}\right)$, 47.8 $\left(\mathrm{C}_{\mathrm{A1}}-\underline{\mathrm{CH}_{2}}\right)$. ESI-HRMS Calcd for $\left(\mathrm{M}+\mathrm{Na}^{+}\right) \mathrm{C}_{21} \mathrm{H}_{21} \mathrm{NO}_{2} \mathrm{Na}: 342.1470$, found: 342.1472 .

$\mathrm{N}$-(4-(Benzyloxy)-3-methoxybenzyl)-4-methoxyaniline (A2B2). 4-benzyloxy-3-methoxy benzaldehyde (110 mg, $0.45 \mathrm{mmol})$; p-anisidine $(62 \mathrm{mg}, 0.5 \mathrm{mmol})$ in dry dichloromethane $(5$ $\mathrm{mL})$; sodium triacetoxyborohydride $(148 \mathrm{mg}, 0.7 \mathrm{mmol})$ and acetic acid $(45 \mu \mathrm{L})$. Purification by column chromatography provides $122 \mathrm{mg}$ (77\%) of the amine A2B2 as a yellow solid. Mp 103$104{ }^{\circ} \mathrm{C} .{ }^{1} \mathrm{H}$ NMR $\left(400 \mathrm{MHz} \mathrm{CDCl}_{3}\right)$ : 7.48-7.34 (m, 5H, aromatic), 7.00-6.61 (m, 7H, aromatic), $5.16\left(\mathrm{~s}, 2 \mathrm{H}, \underline{\mathrm{OCH}}_{2} \mathrm{Ph}\right), 4.19\left(\mathrm{~s}, 2 \mathrm{H}, \mathrm{C}_{\mathrm{A} 3}-\mathrm{OCH}_{3}\right), 3.91\left(\mathrm{~s}, 3 \mathrm{H}, \mathrm{C}_{\mathrm{A} 4}-\mathrm{OCH}_{3}\right), 3.78$ (s, $\left.3 \mathrm{H} \mathrm{C} \mathrm{C}_{\mathrm{B} 4}-\mathrm{OMe}\right)$, 3.54 (bs, $1 \mathrm{H}, \mathrm{NH}) .{ }^{13} \mathrm{C} \mathrm{NMR}\left(100 \mathrm{MHz} \mathrm{CDCl}_{3}\right): 152.1\left(\mathrm{C}_{\mathrm{B} 4}, \mathrm{C}\right), 148.8\left(\mathrm{C}_{\mathrm{A} 4}, \mathrm{C}\right), 148.2\left(\mathrm{C}_{\mathrm{A} 3}, \mathrm{C}\right)$, $142.4\left(\mathrm{C}_{\mathrm{B} 1}, \mathrm{C}\right), 137.0\left(\mathrm{OCH}_{2} \mathrm{Ph}\right), 132.2\left(\mathrm{OCH}_{2} \mathrm{Ph}\right), 128.4\left(\mathrm{OCH}_{2} \mathrm{Ph}\right), 127.7\left(\mathrm{OCH}_{2} \mathrm{Ph}\right), 127.3$ $\left(\mathrm{C}_{\mathrm{A} 6}, \mathrm{CH}\right), 120.2\left(\mathrm{C}_{\mathrm{B} 2}-\mathrm{C}_{\mathrm{B} 6}, \mathrm{CH}\right), 116.3\left(\mathrm{C}_{\mathrm{B} 3}-\mathrm{C}_{\mathrm{B} 5}, \mathrm{CH}\right), 114.8\left(\mathrm{C}_{\mathrm{A} 2}, \mathrm{CH}\right), 114.0\left(\mathrm{C}_{\mathrm{A} 5}, \mathrm{CH}\right), 70.9$ $\left(\mathrm{OCH}_{2} \mathrm{Ph}\right), 55.9\left(\mathrm{C}_{\mathrm{B} 4}-\mathrm{OMe}\right), 55.7\left(\mathrm{C}_{\mathrm{A} 3}-\mathrm{OMe}\right), 48.8\left(\mathrm{C}_{\mathrm{A} 1}-\underline{\mathrm{CH}_{2}}\right)$. ESI-HRMS Calcd for $\left(\mathrm{M}+\mathrm{Na}^{+}\right)$ $\mathrm{C}_{22} \mathrm{H}_{23} \mathrm{NO}_{3} \mathrm{Na}$ : 372.1576 , found: 372.1564 .

$N$-(3,4-Bis(benzyloxy)benzyl)aniline (A3B1). 3,4-bis(benzyloxy)benzaldehyde (106 mg, 0.33 mmol); aniline (44 $\mu \mathrm{L}, 0.37 \mathrm{mmol})$ in dry dichloromethane $(3 \mathrm{~mL})$; sodium triacetoxyborohydride $(109 \mathrm{mg}, 0.51 \mathrm{mmol})$ and acetic acid $(37 \mu \mathrm{L})$. Purification by column chromatography provides $121 \mathrm{mg}$ (92\%) of the amine A3B1 as a white solid. Mp 126-127 ${ }^{\circ} \mathrm{C}$. ${ }^{1} \mathrm{H}$ NMR (400 MHz CDCl 3 ): 7.59-7.29 (m, 13H, aromatic), 7.12-6.72 (m, 5H, aromatic), 5.26 (s, $\left.2 \mathrm{H}, \mathrm{C}_{\mathrm{A} 4}-\mathrm{OCH}_{2} \mathrm{Ph}\right), 5.25\left(\mathrm{~s}, 2 \mathrm{H}, \mathrm{C}_{\mathrm{A} 3}-\mathrm{OCH}_{2} \mathrm{Ph}\right), 4.30\left(\mathrm{~s}, 2 \mathrm{H}, \mathrm{C}_{\mathrm{Al}}-\underline{\mathrm{CH}}_{2}\right), 3.93(\mathrm{~s}, 1 \mathrm{H}, \mathrm{N} \underline{\mathrm{H}}) .{ }^{13} \mathrm{C}$ $\operatorname{NMR}\left(100 \mathrm{MHz} \mathrm{CDCl}_{3}\right): 149.3\left(\mathrm{C}_{\mathrm{B} 1}, \mathrm{C}\right), 148.4\left(\mathrm{C}_{\mathrm{A} 3}-\mathrm{C}_{\mathrm{A} 4}, \mathrm{C}\right), 137.6\left(\mathrm{OCH}_{2} \mathrm{Ph}\right), 133.1\left(\mathrm{C}_{\mathrm{A} 1}, \mathrm{CH}\right)$, $129.4\left(\mathrm{OCH}_{2} \underline{\mathrm{Ph}}\right), 128.6\left(\mathrm{OCH}_{2} \underline{\mathrm{Ph}}\right), 127.6\left(\mathrm{OCH}_{2} \underline{\mathrm{Ph}}\right), 127.5\left(\mathrm{C}_{\mathrm{B} 3}-\mathrm{C}_{\mathrm{B} 5}, \mathrm{CH}\right), 120.6\left(\mathrm{C}_{\mathrm{A} 6}, \mathrm{CH}\right)$, 117.7 ( $\left.\mathrm{C}_{\mathrm{B} 4}, \mathrm{CH}\right), 115.2\left(\mathrm{C}_{\mathrm{A} 5}, \mathrm{CH}\right), 114.7\left(\mathrm{C}_{\mathrm{A} 2}, \mathrm{CH}\right), 113.1\left(\mathrm{C}_{\mathrm{B} 2}-\mathrm{C}_{\mathrm{B} 6}, \mathrm{CH}\right), 71.6\left(\mathrm{C}_{\mathrm{A} 3}-\mathrm{OCH}_{2} \mathrm{Ph}\right)$, 71.4 $\left(\mathrm{C}_{\mathrm{A} 4}-\mathrm{OCH} \underline{\mathrm{CH}}_{2} \mathrm{Ph}\right), 48.1\left(\mathrm{C}_{\mathrm{A1} 1}-\underline{\mathrm{CH}}_{2}\right)$. ESI-HRMS $\left(\mathrm{M}+\mathrm{Na}^{+}\right) \mathrm{C}_{27} \mathrm{H}_{25} \mathrm{NO}_{2} \mathrm{Na}: 418,1783$ found: 418.1771 .

$\mathrm{N}$-(3,4-Bis(benzyloxy)benzyl)-4-methoxyaniline (A3B2). 3,4-bis(benzyloxy)benzaldehyde (110 mg, $0.35 \mathrm{mmol})$; p-anisidine $(47 \mathrm{mg}, 0.38 \mathrm{mmol})$ in dry dichloromethane $(3.5 \mathrm{~mL})$; sodium 
triacetoxyborohydride $(113 \mathrm{mg}, 0.53 \mathrm{mmol})$ and acetic acid $(35 \mu \mathrm{L})$. Purification by column chromatography provides $131 \mathrm{mg}$ (89 \%) of the amine A3B2 as a yellow solid. Mp 132-133 ${ }^{\circ} \mathrm{C}$. ${ }^{1} \mathrm{H} \mathrm{NMR}\left(400 \mathrm{MHz} \mathrm{CDCl}_{3}\right): 7.52-7.36(\mathrm{~m}, 10 \mathrm{H}$, aromatic), 7.06-6.62 (m, 7H, aromatic), 5.20 (s, $\left.2 \mathrm{H}, \mathrm{C}_{\mathrm{A} 3}-\mathrm{OCH}_{2} \underline{\mathrm{Ph}}\right), 5.19\left(\mathrm{~s}, 2 \mathrm{H}, \mathrm{C}_{\mathrm{A} 4}-\mathrm{OCH}_{2} \underline{\mathrm{Ph}}\right), 4.21\left(\mathrm{~s}, 2 \mathrm{H}, \mathrm{C}_{\mathrm{A} 3} \mathrm{OCH}_{2} \mathrm{Ph}\right), 3.79\left(\mathrm{~s}, 3 \mathrm{H}, \mathrm{C}_{\mathrm{B} 4} \mathrm{O}-\right.$ Me). ${ }^{13} \mathrm{C}$ NMR (100 MHz CDCl $): 152.1\left(\mathrm{C}_{\mathrm{B} 4}, \mathrm{C}\right), 149.1\left(\mathrm{C}_{\mathrm{A} 3}, \mathrm{C}\right), 148.1\left(\mathrm{C}_{\mathrm{A} 4}, \mathrm{C}\right), 142.4\left(\mathrm{C}_{\mathrm{B} 1}\right.$, C), $137.2\left(\mathrm{OCH}_{2} \underline{\mathrm{Ph}}\right), 133.1\left(\mathrm{OCH}_{2} \underline{\mathrm{Ph}}\right), 128.4\left(\mathrm{OCH}_{2} \underline{\mathrm{Ph}}\right), 127.7\left(\mathrm{OCH}_{2} \underline{\mathrm{Ph}}\right), 127.2\left(\mathrm{OCH}_{2} \underline{\mathrm{Ph}}\right)$, $120.4\left(\mathrm{C}_{\mathrm{A} 6}, \mathrm{CH}\right), 115.3\left(\mathrm{C}_{\mathrm{B} 2}-\mathrm{C}_{\mathrm{B} 6}, \mathrm{CH}\right), 114.9\left(\mathrm{C}_{\mathrm{B} 3}-\mathrm{C}_{\mathrm{B} 5}, \mathrm{CH}\right), 114.6\left(\mathrm{C}_{\mathrm{A} 5}, \mathrm{CH}\right), 114.1\left(\mathrm{C}_{\mathrm{A} 2}, \mathrm{CH}\right)$, $71.4\left(\mathrm{C}_{\mathrm{A} 4}-\mathrm{OCH}_{2} \mathrm{Ph}\right), 71.2\left(\mathrm{C}_{\mathrm{A} 3}-\underline{\mathrm{OCH}}_{2} \mathrm{Ph}\right), 55.7\left(\mathrm{C}_{\mathrm{B} 4}-\mathrm{OMe}\right), 48.9\left(\mathrm{C}_{\mathrm{A} 1}-\underline{\mathrm{CH}_{2}}\right)$. ESI-HRMS Calcd for $\left(\mathrm{M}+\mathrm{Na}^{+}{ }^{+} \mathrm{C}_{28} \mathrm{H}_{27} \mathrm{NO}_{3} \mathrm{Na}\right.$ : 448.1889 , found: 448.1908 .

\section{General procedure for microwave $\boldsymbol{N}$-alkylation}

To a solution of amine (1 eq.) in dry acetontrile prepared inside the microwave reaction tube, anh. $\mathrm{K}_{2} \mathrm{CO}_{3}$ (1.3 eq.) and benzyl bromide (1.3 eq.) were added. The sealed tube was heated on the microwave reactor using the microwave settings describe below. The reaction mixture was poured into $30 \mathrm{~mL}$ of brine extracted with dichloromethane $(4 \times 10 \mathrm{~mL})$. Combined organic extracts were dried over magnesium sulfate and evaporated. The compound was purified by flash column chromatography.

Microwave settings:

Temp $=150^{\circ} \mathrm{C}$, Power: $100 \mathrm{~W}$, Run time $=10 \mathrm{~min}$, Hold time $=20 \mathrm{~min}$.

Table 3. Microwave $N$-alkylation of AB secondary amines

\begin{tabular}{|c|c|c|c|c|}
\hline Secondary amine & Acetonitrile & $\mathrm{K}_{2} \mathrm{CO}_{3}$ & $\mathrm{R}-\mathrm{Br}$ & $\begin{array}{l}\text { Isolated } \\
\text { product }\end{array}$ \\
\hline $\begin{array}{c}\text { A1B1 } \\
56 \mathrm{mg}, 0.23 \mathrm{mmol}\end{array}$ & $3 \mathrm{~mL}$ & $\begin{array}{c}54 \mathrm{mg}, 0.39 \\
\mathrm{mmol}\end{array}$ & $\begin{array}{c}\mathrm{BnBr} \\
36 \mu \mathrm{L}, 0.30 \mathrm{mmol}\end{array}$ & $\begin{array}{c}\text { A1B1C1 } \\
70 \mathrm{mg}(91 \%)\end{array}$ \\
\hline $\begin{array}{c}\text { A1B1 } \\
61 \mathrm{mg}, 0.25 \mathrm{mmol}\end{array}$ & $3 \mathrm{~mL}$ & $\begin{array}{c}58 \mathrm{mg}, 0.42 \\
\mathrm{mmol}\end{array}$ & $\begin{array}{c}\mathrm{PhCH}_{2} \mathrm{CH}_{2} \mathrm{Br} \\
45 \mu \mathrm{L}, 0.33 \mathrm{mmol}\end{array}$ & $\begin{array}{c}\text { A1B1C2 } \\
76 \mathrm{mg}(87 \%)\end{array}$ \\
\hline $\begin{array}{c}\text { A1B2 } \\
60 \mathrm{mg}, 0.22 \mathrm{mmol}\end{array}$ & $3 \mathrm{~mL}$ & $\begin{array}{c}51 \mathrm{mg}, 0.37 \\
\mathrm{mmol}\end{array}$ & $\begin{array}{c}\mathrm{BnBr} \\
45 \mu \mathrm{L}, 0.33 \mathrm{mmol}\end{array}$ & $\begin{array}{c}\text { A1B2C1 } \\
72 \mathrm{mg}(90 \%)\end{array}$ \\
\hline $\begin{array}{c}\text { A1B2 } \\
60 \mathrm{mg}, 0.22 \mathrm{mmol}\end{array}$ & $3 \mathrm{~mL}$ & $\begin{array}{c}51 \mathrm{mg}, 0.37 \\
\mathrm{mmol}\end{array}$ & $\begin{array}{c}\mathrm{PhCH}_{2} \mathrm{CH}_{2} \mathrm{Br} \\
39 \mu \mathrm{L}, 0.29 \mathrm{mmol}\end{array}$ & $\begin{array}{c}\text { A1B2C2 } \\
75 \mathrm{mg}(91 \%)\end{array}$ \\
\hline $\begin{array}{c}\text { A2B1 } \\
56 \mathrm{mg}, 0.18 \mathrm{mmol}\end{array}$ & $3 \mathrm{~mL}$ & $\begin{array}{c}41 \mathrm{mg}, 0.30 \\
\mathrm{mmol}\end{array}$ & $\begin{array}{c}\mathrm{BnBr} \\
27 \mu \mathrm{L}, 0.23 \mathrm{mmol}\end{array}$ & $\begin{array}{c}\text { A2B1C1 } \\
58 \mathrm{mg}(81 \%)\end{array}$ \\
\hline $\begin{array}{c}\text { A2B1 } \\
61 \mathrm{mg}, 0.19 \mathrm{mmol}\end{array}$ & $3 \mathrm{~mL}$ & $\begin{array}{c}45 \mathrm{mg}, 0.32 \\
\mathrm{mmol}\end{array}$ & $\begin{array}{c}\mathrm{PhCH}_{2} \mathrm{CH}_{2} \mathrm{Br} \\
34 \mu \mathrm{L}, 0.25 \mathrm{mmol}\end{array}$ & $\begin{array}{c}\text { A2B1C2 } \\
71 \mathrm{mg}(88 \%)\end{array}$ \\
\hline $\begin{array}{c}\text { A2B2 } \\
68 \mathrm{mg}, 0.19 \mathrm{mmol}\end{array}$ & $3 \mathrm{~mL}$ & $\begin{array}{c}45 \mathrm{mg}, 0.33 \\
\mathrm{mmol}\end{array}$ & $\begin{array}{c}\mathrm{BnBr} \\
30 \mu \mathrm{L}, 0.25 \mathrm{mmol}\end{array}$ & $\begin{array}{c}\text { A2B2C1 } \\
72 \mathrm{mg}(84 \%)\end{array}$ \\
\hline $\begin{array}{c}\text { A2B2 } \\
70 \mathrm{mg}, 0.18 \mathrm{mmol}\end{array}$ & $3 \mathrm{~mL}$ & $\begin{array}{c}41 \mathrm{mg}, \\
0.30 \mathrm{mmol}\end{array}$ & $\begin{array}{c}\mathrm{PhCH}_{2} \mathrm{CH}_{2} \mathrm{Br} \\
32 \mu \mathrm{L}, 0.23 \mathrm{mmol}\end{array}$ & $\begin{array}{c}\text { A2B2C2 } \\
69 \mathrm{mg}(86 \%)\end{array}$ \\
\hline
\end{tabular}


Table 3. (Continued)

\begin{tabular}{|c|c|c|c|c|}
\hline $\begin{array}{c}\text { A3B1 } \\
70 \mathrm{mg}, 0.18 \mathrm{mmol}\end{array}$ & $3 \mathrm{~mL}$ & $\begin{array}{c}41 \mathrm{mg}, 0.30 \\
\mathrm{mmol}\end{array}$ & $\begin{array}{c}\mathrm{BnBr} \\
27 \mu \mathrm{L}, 0.23 \mathrm{mmol}\end{array}$ & $\begin{array}{c}\text { A3B1C1 } \\
60 \mathrm{mg}(83 \%)\end{array}$ \\
\hline $\begin{array}{c}\text { A3B1 } \\
74 \mathrm{mg}, 0.19 \mathrm{mmol}\end{array}$ & $3 \mathrm{~mL}$ & $\begin{array}{c}44 \mathrm{mg}, 0.32 \\
\mathrm{mmol}\end{array}$ & $\begin{array}{c}\mathrm{PhCH}_{2} \mathrm{CH}_{2} \mathrm{Br} \\
33 \mu \mathrm{L}, 0.24 \mathrm{mmol}\end{array}$ & $\begin{array}{c}\text { A3B1C2 } \\
69 \mathrm{mg}(87 \%)\end{array}$ \\
\hline $\begin{array}{c}\text { A3B2 } \\
53 \mathrm{mg}, 0.13 \mathrm{mmol}\end{array}$ & $3 \mathrm{~mL}$ & $\begin{array}{c}31 \mathrm{mg}, 0.23 \\
\mathrm{mmol}\end{array}$ & $\begin{array}{c}\mathrm{BnBr} \\
21 \mu \mathrm{L}, 0.17 \mathrm{mmol}\end{array}$ & $\begin{array}{c}\text { A3B2C1 } \\
46 \mathrm{mg}(78 \%)\end{array}$ \\
\hline $\begin{array}{c}\text { A3B2 } \\
52 \mathrm{mg}, 0.13 \mathrm{mmol}\end{array}$ & $3 \mathrm{~mL}$ & $\begin{array}{c}31 \mathrm{mg}, 0.22 \\
\mathrm{mmol}\end{array}$ & $\begin{array}{c}\mathrm{PhCH}_{2} \mathrm{CH}_{2} \mathrm{Br} \\
23 \mu \mathrm{L}, 0.17 \mathrm{mmol}\end{array}$ & $\begin{array}{c}\text { A3B2C2 } \\
46 \mathrm{mg}(77 \%) \\
\end{array}$ \\
\hline
\end{tabular}

$\boldsymbol{N}$-Benzyl- $\boldsymbol{N}$-(3,4-dimethoxybenzyl)aniline (A1B1C1). Yellowish oil. ${ }^{1} \mathrm{H}$ NMR (300 $\mathrm{MHz}$ $\left.\mathrm{CDCl}_{3}\right)$ : 7.37-7.19 (m, 7H, aromatic), 6.83-6.72 (m, $5 \mathrm{H}$, aromatic), $4.65\left(\mathrm{~s}, 2 \mathrm{H}, \mathrm{C}_{\mathrm{Al} 1}-\mathrm{CH}_{2}\right), 4.61$ (s, $\left.2 \mathrm{H}, \mathrm{C}_{\mathrm{C} 1}-\mathrm{CH}_{2}\right), 3.89$ (s, 3H, $\left.\mathrm{C}_{\mathrm{A} 3}-\mathrm{OMe}\right), 3.82\left(\mathrm{~s}, 3 \mathrm{H}, \mathrm{C}_{\mathrm{A} 4}-\mathrm{OMe}\right) .{ }^{13} \mathrm{C} \mathrm{NMR}\left(75 \mathrm{MHz} \mathrm{CDCl}_{3}\right)$ : $149.4\left(\mathrm{C}_{\mathrm{A} 3}, \mathrm{C}\right), 149.3\left(\mathrm{C}_{\mathrm{B} 1}, \mathrm{C}\right), 148.0\left(\mathrm{C}_{\mathrm{A} 4}, \mathrm{C}\right), 138.7\left(\mathrm{C}_{\mathrm{C} 1}, \mathrm{C}\right), 131.1\left(\mathrm{C}_{\mathrm{B} 6}, \mathrm{CH}\right), 129.2\left(\mathrm{C}_{\mathrm{B} 3}-\mathrm{C}_{\mathrm{B} 5}\right.$ ,CH), 128.6 $\left(\mathrm{C}_{\mathrm{C} 3}-\mathrm{C}_{\mathrm{C} 5}, \mathrm{CH}\right), 126.9\left(\mathrm{C}_{\mathrm{C}^{2}-} \mathrm{C}_{\mathrm{C} 6}, \mathrm{CH}\right), 126.8\left(\mathrm{C}_{\mathrm{C} 4}, \mathrm{CH}\right), 118.8\left(\mathrm{C}_{\mathrm{A} 6}, \mathrm{CH}\right), 116.9\left(\mathrm{C}_{\mathrm{A} 4}\right.$, $\mathrm{C}), 112.7\left(\mathrm{C}_{\mathrm{B} 2}-\mathrm{C}_{\mathrm{B} 6}, \mathrm{CH}\right), 111.3\left(\mathrm{C}_{\mathrm{A} 2}, \mathrm{CH}\right), 110.0\left(\mathrm{C}_{\mathrm{A} 5}, \mathrm{C}\right), 56.0\left(\mathrm{C}_{\mathrm{A} 3}-\mathrm{OMe}\right), 55.9\left(\mathrm{C}_{\mathrm{A} 4}-\mathrm{OMe}\right)$, $54.2\left(\mathrm{C}_{\mathrm{A1}}-\mathrm{CH}_{2}\right), 54.1\left(\mathrm{C}_{\mathrm{Cl} 1}-\mathrm{CH}_{2}\right)$. ESI-HRMS Calcd for $\left(\mathrm{M}+\mathrm{Na}^{+}\right) \mathrm{C}_{22} \mathrm{H}_{23} \mathrm{NO}_{2} \mathrm{Na}$ : 356.1626, found: 356.1641 .

$\mathrm{N}$-(3,4-Dimethoxybenzyl)- $\mathrm{N}$-phenethylaniline (A1B1C2). White solid. Mp $92-94{ }^{\circ} \mathrm{C}$.

${ }^{1} \mathrm{H}$ NMR (300 MHz CDCl $)$ : 7.34-7.21 (m, 8H, aromatic), 6.81-6.74 (m, 5H, aromatic), 4.45 (s, $2 \mathrm{H}, \mathrm{C}_{\mathrm{A} 1}-\underline{\mathrm{CH}_{2}}$ ), 3.88 (s, $3 \mathrm{H}, \mathrm{C}_{\mathrm{A} 3}-\mathrm{OMe}$ ), 3.83 (s, 3H, $\left.\mathrm{C}_{\mathrm{A} 4}-\mathrm{OMe}\right), 3.65$ (dd, $2 \mathrm{H}, J=7.56$ and 8.05, $\mathrm{C}_{\mathrm{Cl}}-\mathrm{CH}_{2} \mathrm{CH}_{2} \mathrm{Ph}$ ), 2.95 (dd, $2 \mathrm{H}, J=8.06$ and 7.55, $\left.\mathrm{C}_{\mathrm{Cl} 1}-\mathrm{CH}_{2} \mathrm{CH}_{2} \mathrm{Ph}\right) .{ }^{13} \mathrm{C}$ NMR (75 MHz CDCl 3 ): 149.2 ( $\left.\mathrm{C}_{\mathrm{A} 3}, \mathrm{C}\right), 148.4\left(\mathrm{C}_{\mathrm{A} 4}, \mathrm{C}\right), 147.9\left(\mathrm{C}_{\mathrm{B} 1}, \mathrm{C}\right), 139.6\left(\mathrm{C}_{\mathrm{C} 1}, \mathrm{C}\right), 131.3\left(\mathrm{C}_{\mathrm{A} 1}, \mathrm{CH}\right), 129.3\left(\mathrm{C}_{\mathrm{B} 3}-\mathrm{C}_{\mathrm{B} 5}\right.$, $\mathrm{CH}), 128.8\left(\mathrm{C}_{\mathrm{C} 2}-\mathrm{C}_{\mathrm{C} 6}, \mathrm{CH}\right), 128.6\left(\mathrm{C}_{\mathrm{C} 3}-\mathrm{C}_{\mathrm{C} 5}, \mathrm{CH}\right), 126.3\left(\mathrm{C}_{\mathrm{C} 4}, \mathrm{CH}\right), 118.7\left(\mathrm{C}_{\mathrm{A} 6}, \mathrm{CH}\right), 116.5\left(\mathrm{C}_{\mathrm{B} 4}\right.$, $\mathrm{CH}), 112.5\left(\mathrm{C}_{\mathrm{B} 2}-\mathrm{C}_{\mathrm{B} 6}, \mathrm{CH}\right), 111.3\left(\mathrm{C}_{\mathrm{A} 5}, \mathrm{CH}\right), 109.8\left(\mathrm{C}_{\mathrm{A} 2}, \mathrm{C}\right), 56.0\left(\mathrm{C}_{\mathrm{A} 4}-\mathrm{OMe}\right), 55.9\left(\mathrm{C}_{\mathrm{A} 3}-\mathrm{OMe}\right)$, $54.3\left(\mathrm{C}_{\mathrm{A} 1}-\mathrm{CH}_{2}\right), 52.8\left(\mathrm{C}_{\mathrm{Cl} 1}-\mathrm{CH}_{2} \mathrm{CH}_{2} \mathrm{Ph}\right), 33.4\left(\mathrm{C}_{\mathrm{Cl} 1}-\mathrm{CH}_{2} \mathrm{CH}_{2} \mathrm{Ph}\right)$. ESI-HRMS Calcd for $\left(\mathrm{M}+\mathrm{Na}^{+}\right)$ $\mathrm{C}_{23} \mathrm{H}_{25} \mathrm{NO}_{2} \mathrm{Na}$ : 370.1778 , found: 370.1772 .

$\mathrm{N}$-Benzyl- $\mathrm{N}$-(3,4-dimethoxybenzyl)-4-methoxyaniline (A1B2C1). Yellow oil. ${ }^{1} \mathrm{H}$ NMR (300 $\mathrm{MHz} \mathrm{CDCl}_{3}$ ): 7.41-7.27 (m, $5 \mathrm{H}$, aromatic), 6.85-6.74 (m, $7 \mathrm{H}$, aromatic), 4.55 (s, $2 \mathrm{H}, \mathrm{C}_{\mathrm{A1} 1}-\mathrm{CH}_{2}$ ), $4.51\left(\mathrm{~s}, 2 \mathrm{H}, \mathrm{C}_{\mathrm{Cl}_{1}-\mathrm{CH}_{2}}\right), 3.89$ (s, 3H, $\left.\mathrm{C}_{\mathrm{A} 3}-\mathrm{OMe}\right), 3.82$ (s, 3H, $\left.\mathrm{C}_{\mathrm{A} 4}-\mathrm{OMe}\right), 3.76$ (s, 3H, $\mathrm{C}_{\mathrm{B} 4-}-\underline{\mathrm{OMe}}$ ). LC-ESI-MS $\left(\mathrm{M}+\mathrm{H}^{+}\right)$: 363.11 . 
$\boldsymbol{N}$-(3,4-Dimethoxybenzyl)-4-methoxy- $\boldsymbol{N}$-phenethylaniline (A1B2C2). Yellow oil.

${ }^{1} \mathrm{H}$ NMR (300 MHz $\mathrm{CDCl}_{3}$ ): 7.34-7.20 (m, 5H, aromatic), 6.89-6.79 (m, 7H, aromatic), 4.38 (s, $\left.2 \mathrm{H}, \mathrm{C}_{\mathrm{A} 1}-\underline{\mathrm{CH}_{2}}\right), 3.89$ (s, 3H C $\left.\mathrm{A}_{4}-\mathrm{OMe}\right), 3.84$ (s, 3H, $\left.\mathrm{C}_{\mathrm{A} 3}-\mathrm{OMe}\right), 3.79$ (s, 3H, $\left.\mathrm{C}_{\mathrm{B} 4}-\mathrm{OMe}\right), 3.58$ (dd, $2 \mathrm{H}, J=8.06$ and 7.55, $\left.\mathrm{C}_{\mathrm{C} 1}-\underline{\mathrm{CH}}_{2} \mathrm{CH}_{2} \mathrm{Ph}\right), 2.92\left(\mathrm{dd}, 2 \mathrm{H}, J=8.05\right.$ and $\left.7.06, \mathrm{C}_{\mathrm{C} 1}-\mathrm{CH}_{2} \underline{\mathrm{CH}}_{2} \mathrm{Ph}\right) .{ }^{13} \mathrm{C}$ NMR (75 MHz CDCl $)$ : $151.8\left(\mathrm{C}_{\mathrm{B} 4}, \mathrm{C}\right), 149.1\left(\mathrm{C}_{\mathrm{A} 3}, \mathrm{C}\right), 147.9\left(\mathrm{C}_{\mathrm{A} 4}, \mathrm{C}\right), 143.2\left(\mathrm{C}_{\mathrm{A} 1}, \mathrm{C}\right), 139.9$ $\left(\mathrm{C}_{\mathrm{C} 1}, \mathrm{C}\right), 131.7\left(\mathrm{C}_{\mathrm{A} 1}, \mathrm{C}\right), 128.8\left(\mathrm{C}_{\mathrm{C} 2}-\mathrm{C}_{\mathrm{C} 6}, \mathrm{CH}\right), 128.5\left(\mathrm{C}_{\mathrm{C} 3}-\mathrm{C}_{\mathrm{C} 5}, \mathrm{CH}\right), 126.2\left(\mathrm{C}_{\mathrm{C} 4}, \mathrm{CH}\right), 119.0$ $\left(\mathrm{C}_{\mathrm{A} 6}, \mathrm{CH}\right), 115.0\left(\mathrm{C}_{\mathrm{B} 2}-\mathrm{C}_{\mathrm{B} 6}, \mathrm{CH}\right), 114.9\left(\mathrm{C}_{\mathrm{B} 3}-\mathrm{C}_{\mathrm{B} 5}, \mathrm{CH}\right), 111.2\left(\mathrm{C}_{\mathrm{A} 5}, \mathrm{CH}\right), 110.2\left(\mathrm{C}_{\mathrm{A} 2}, \mathrm{CH}\right), 55.9$ $\left(\mathrm{C}_{\mathrm{B} 4}-\mathrm{OMe}\right), 55.8\left(\mathrm{C}_{\mathrm{A} 4}-\mathrm{OMe}\right), 55.8\left(\mathrm{C}_{\mathrm{A} 3}-\mathrm{OMe}\right), 55.5\left(\mathrm{C}_{\mathrm{A} 1}-\underline{\mathrm{CH}_{2}}\right), 53.5\left(\mathrm{C}_{\mathrm{Cl}_{1}}-\underline{\mathrm{CH}_{2}}{ }_{2} \mathrm{CH}_{2} \mathrm{Ph}\right), 33.4$ $\left(\mathrm{C}_{\mathrm{C} 1}-\mathrm{CH}_{2} \underline{\mathrm{CH}}_{2} \mathrm{Ph}\right)$. ESI-HRMS Calcd for $\left(\mathrm{M}+\mathrm{H}^{+}\right) \mathrm{C}_{24} \mathrm{H}_{28} \mathrm{NO}_{3}: 378.2069$, found: 378.2087.

$\boldsymbol{N}$-Benzyl- $\boldsymbol{N}$-(4-(benzyloxy)-3-methoxybenzyl)aniline (A2B1C1). White solid. Mp 105-106 ${ }^{\circ} \mathrm{C}$. ${ }^{1} \mathrm{H}$ NMR (300 $\mathrm{MHz} \mathrm{CDCl}_{3}$ ): 7.37-7.19 (m, 12H, aromatic), 6.86-6.74 (m, 6H, aromatic), 5.10 (s, $\left.2 \mathrm{H}, \mathrm{OCH}_{2} \mathrm{Ph}\right), 4.55\left(\mathrm{~s}, 2 \mathrm{H}, \mathrm{C}_{\mathrm{A1} 1}-\underline{\mathrm{CH}_{2}}\right), 4.53\left(\mathrm{~s}, 2 \mathrm{H}, \mathrm{C}_{\mathrm{C} 1}-\underline{\mathrm{CH}}_{2}\right), 3.91\left(\mathrm{~s}, 3 \mathrm{H}, \mathrm{C}_{\mathrm{A} 3}-\mathrm{OMe}\right) .{ }^{13} \mathrm{C} \mathrm{NMR}$ (75 MHz $\left.\mathrm{CDCl}_{3}\right):{ }^{13} \mathrm{C} \mathrm{NMR}\left(75 \mathrm{MHz} \mathrm{CDCl}_{3}\right): 149.5\left(\mathrm{C}_{\mathrm{A} 4}-\mathrm{C}_{\mathrm{B} 1}, \mathrm{C}\right), 147.5\left(\mathrm{C}_{\mathrm{A} 3}, \mathrm{C}\right), 138.8\left(\mathrm{C}_{\mathrm{C} 1}\right.$, C), $137.3\left(\mathrm{C}_{\mathrm{A} 1}, \mathrm{C}\right), 134.5\left(\mathrm{OCH}_{2} \underline{\mathrm{Ph}}\right), 129.4\left(\mathrm{C}_{\mathrm{B} 3}-\mathrm{C}_{\mathrm{B} 5}, \mathrm{CH}\right), 128.6\left(\mathrm{C}_{\mathrm{C} 3}-\mathrm{C}_{\mathrm{C} 5}, \mathrm{CH}\right), 128.5$ $\left(\mathrm{OCH}_{2} \underline{\mathrm{Ph}}\right), 127.7\left(\mathrm{OCH}_{2} \underline{\mathrm{Ph}}\right), 127.5\left(\mathrm{C}_{\mathrm{C} 4}, \mathrm{CH}\right), 126.9\left(\mathrm{C}_{\mathrm{B} 4}, \mathrm{CH}\right), 126.7\left(\mathrm{C}_{\mathrm{C} 2}-\mathrm{C}_{\mathrm{C} 6}, \mathrm{CH}\right), 121.4$ $\left(\mathrm{C}_{\mathrm{A} 6}, \mathrm{CH}\right), 115.3\left(\mathrm{C}_{\mathrm{A} 2}, \mathrm{CH}\right), 112.6\left(\mathrm{C}_{\mathrm{B} 2}-\mathrm{C}_{\mathrm{B} 6}, \mathrm{CH}\right), 111.9\left(\mathrm{C}_{\mathrm{A} 5}, \mathrm{CH}\right), 71.0\left(\mathrm{OCH}_{2} \mathrm{Ph}\right), 56.0\left(\mathrm{C}_{\mathrm{A} 3}{ }^{-}\right.$ $\mathrm{OMe}), 54.4\left(\mathrm{C}_{\mathrm{A} 1}-\underline{\mathrm{CH}}_{2}\right), 54.3\left(\mathrm{C}_{\mathrm{C} 1}-\underline{\mathrm{CH}_{2}}\right)$. ESI-HRMS Calcd for $\left(\mathrm{M}+\mathrm{Na}^{+}\right) \mathrm{C}_{28} \mathrm{H}_{28} \mathrm{NO}_{2} \mathrm{Na}$ : 432.1934, found: 432.1923.

$\mathrm{N}$-(4-(Benzyloxy)-3-methoxybenzyl)- $\mathrm{N}$-phenethylaniline (A2B1C2). White solid. Mp 77.5$78.5{ }^{\circ} \mathrm{C} .{ }^{1} \mathrm{H}$ NMR (400 MHz $\mathrm{CDCl}_{3}$ ): 7.37-7.18 (m, 14H, aromatic), 6.85-6.74 (m, 4H, aromatic), $5.09\left(\mathrm{~s}, 2 \mathrm{H}, \underline{\mathrm{OCH}}_{2} \mathrm{Ph}\right), 4.38\left(\mathrm{~s}, 2 \mathrm{H} \mathrm{C} \mathrm{C}_{\mathrm{A} 1}-\underline{\mathrm{CH}}_{2}\right), 3.89$ (s, 3H, $\left.\mathrm{C}_{\mathrm{A} 4}-\mathrm{OMe}\right), 3.60$ (dd, $2 \mathrm{H}, J=8.06$ and

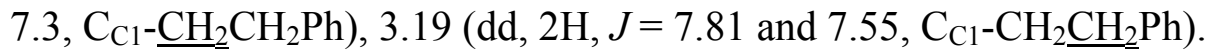

${ }^{13} \mathrm{C}$ NMR (100 MHz $\left.\mathrm{CDCl}_{3}\right): 148.6\left(\mathrm{C}_{\mathrm{A} 4}, \mathrm{C}\right), 148.3\left(\mathrm{C}_{\mathrm{A} 3}, \mathrm{C}\right), 139.6\left(\mathrm{C}_{\mathrm{B} 1}, \mathrm{C}\right), 137.1\left(\mathrm{C}_{\mathrm{C} 1}, \mathrm{C}\right)$, $131.3\left(\mathrm{C}_{\mathrm{A} 1}, \mathrm{C}\right), 129.3\left(\mathrm{OCH}_{2} \underline{\mathrm{Ph}}\right), 128.8\left(\mathrm{C}_{\mathrm{C} 3}-\mathrm{C}_{\mathrm{C} 5}, \mathrm{CH}\right), 128.5\left(\mathrm{C}_{\mathrm{C} 2}-\mathrm{C}_{\mathrm{C} 6}, \mathrm{CH}\right), 127.8\left(\mathrm{C}_{\mathrm{C} 3}-\mathrm{C}_{\mathrm{C} 5}\right.$, $\mathrm{CH}), 127.4\left(\mathrm{OCH}_{2} \underline{\mathrm{Ph}}\right), 126.2\left(\mathrm{C}_{\mathrm{C} 4}, \mathrm{CH}\right), 119.3\left(\mathrm{C}_{\mathrm{A} 6}, \mathrm{CH}\right), 116.4\left(\mathrm{C}_{\mathrm{B} 4}, \mathrm{CH}\right), 112.8\left(\mathrm{C}_{\mathrm{B} 3}-\mathrm{C}_{\mathrm{B} 5}, \mathrm{CH}\right)$, $112.3\left(\mathrm{C}_{\mathrm{B} 2}-\mathrm{C}_{\mathrm{B} 6}, \mathrm{CH}\right), 111.9\left(\mathrm{C}_{\mathrm{A} 5}, \mathrm{CH}\right), 71.0\left(\underline{\mathrm{OCH}} \underline{\mathrm{H}}_{2} \mathrm{Ph}\right), 56.1\left(\mathrm{C}_{\mathrm{A} 3}-\mathrm{OMe}\right), 54.0\left(\mathrm{C}_{\mathrm{A} 1}-\underline{\mathrm{CH}_{2}}\right), 52.7$ $\left(\mathrm{C}_{\mathrm{C} 1}-\underline{\mathrm{CH}_{2}} \mathrm{CH}_{2} \mathrm{Ph}\right), 33.4\left(\mathrm{C}_{\mathrm{C} 1}-\mathrm{CH}_{2} \underline{\mathrm{CH}}_{2} \mathrm{Ph}\right)$

LC-ESI-MS $\left(\mathrm{M}+\mathrm{H}^{+}\right): 424.13$.

$N$-Benzyl- $N$-(4-(benzyloxy)-3-methoxybenzyl)-4-methoxyaniline (A2B2C1). Colorless oil.

${ }^{1} \mathrm{H}$ NMR (300 $\mathrm{MHz} \mathrm{CDCl}_{3}$ ): 7.39-7.22 (m, 10H, aromatic), 6.87-6.68 (m, 7H, aromatic), 5.09 (s, $\left.2 \mathrm{H}, \underline{\mathrm{OCH}}_{2} \mathrm{Ph}\right), 4.44$ (s, 4H, $\left.\mathrm{C}_{\mathrm{A1} 1}-\underline{\mathrm{CH}_{2}} ; \mathrm{C}_{\mathrm{Cl}}-\underline{\mathrm{CH}_{2}}\right), 3.90$ (s, 3H, $\left.\mathrm{C}_{\mathrm{B} 4}-\mathrm{OMe}\right), 3.77$ (s, 3H, C $\underline{\mathrm{B}}_{4}-\mathrm{OMe}$ ). ${ }^{13} \mathrm{C}$ NMR $\left(75 \mathrm{MHz} \mathrm{CDCl}_{3}\right): 151.8\left(\mathrm{C}_{\mathrm{B} 4}, \mathrm{C}\right), 148.5\left(\mathrm{C}_{\mathrm{A} 4}, \mathrm{C}\right), 148.2\left(\mathrm{C}_{\mathrm{A} 3}, \mathrm{C}\right), 143.9\left(\mathrm{C}_{\mathrm{B} 1}, \mathrm{C}\right), 139.1$ $\left(\mathrm{C}_{\mathrm{Cl}}, \mathrm{C}\right), 137.2\left(\mathrm{C}_{\mathrm{A} 1}, \mathrm{C}\right), 131.3\left(\mathrm{OCH}_{2} \underline{\mathrm{Ph}}\right), 128.5\left(\mathrm{OCH}_{2} \underline{\mathrm{Ph}}\right), 128.1\left(\mathrm{OCH}_{2} \underline{\mathrm{Ph}}\right), 127.7\left(\mathrm{OCH}_{2} \underline{\mathrm{Ph}}\right)$, $127.3\left(\mathrm{OCH}_{2} \underline{\mathrm{Ph}}\right), 127.0\left(\mathrm{C}_{\mathrm{C} 6}-\mathrm{C}_{\mathrm{C} 2}, \mathrm{CH}\right), 126.8\left(\mathrm{C}_{\mathrm{C} 4}, \mathrm{CH}\right), 119.6\left(\mathrm{C}_{\mathrm{A} 6}, \mathrm{CH}\right), 114.8\left(\mathrm{C}_{\mathrm{B} 3}-\mathrm{C}_{\mathrm{B} 5}, \mathrm{CH}\right)$, $114.7\left(\mathrm{C}_{\mathrm{B} 2}-\mathrm{C}_{\mathrm{B} 6}, \mathrm{CH}\right), 113.1\left(\mathrm{C}_{\mathrm{A} 5}, \mathrm{CH}\right), 111.8\left(\mathrm{C}_{\mathrm{A} 2}, \mathrm{CH}\right), 70.9\left(\underline{\mathrm{OCH}}_{2} \mathrm{Ph}\right), 56.1\left(\mathrm{C}_{\mathrm{A} 3}-\mathrm{OMe}\right), 55.7$ $\left(\mathrm{C}_{\mathrm{B} 4}-\mathrm{OMe}\right), 54.9\left(\mathrm{C}_{\mathrm{A} 1}-\underline{\mathrm{CH}_{2}}\right), 54.7\left(\mathrm{C}_{\mathrm{C} 1}-\underline{\mathrm{CH}_{2}}\right)$. ESI-HRMS Calcd for $\left(\mathrm{M}+\mathrm{Na}^{+}\right) \mathrm{C}_{29} \mathrm{H}_{29} \mathrm{NO}_{3} \mathrm{Na}$ : 462.2040, found: 462.2035 .

$\boldsymbol{N}$-(4-(Benzyloxy)-3-methoxybenzyl)-4-methoxy- $\boldsymbol{N}$-phenethylaniline (A2B2C2). Yellow oil. ${ }^{1} \mathrm{H}$ NMR (400 $\mathrm{MHz} \mathrm{CDCl}_{3}$ ): 7.44-7.20 (m, 12H, aromatic), 6.90-6.76 (m, 5H, aromatic), 5.13 (s, $\left.2 \mathrm{H}, \underline{\mathrm{OCH}}_{2} \mathrm{Ph}\right), 4.35\left(\mathrm{~s}, 2 \mathrm{H}, \mathrm{C}_{\mathrm{A} 1}-\underline{\mathrm{CH}_{2}}\right), 3.92\left(\mathrm{~s}, 3 \mathrm{H}, \mathrm{C}_{\mathrm{A} 3}-\mathrm{OMe}\right), 3.82\left(\mathrm{~s}, 3 \mathrm{H}, \mathrm{C}_{\mathrm{B} 4}-\mathrm{OMe}\right), 3.52$ (dd, 
$2 \mathrm{H}, J=7.81$ and 7.80, $\left.\mathrm{C}_{\mathrm{C} 1}-\mathrm{CH}_{2} \mathrm{CH}_{2} \mathrm{Ph}\right), 2.95$ (dd, $2 \mathrm{H}, J=8.06$ and $\left.7.30, \mathrm{C}_{\mathrm{C} 1}-\mathrm{CH}_{2} \mathrm{CH}_{2} \mathrm{Ph}\right) .{ }^{13} \mathrm{C}$ NMR (100 MHz CDCl $\left.)_{3}\right): 151.8\left(\mathrm{C}_{\mathrm{B} 4}, \mathrm{C}\right), 148.7\left(\mathrm{C}_{\mathrm{A} 3}, \mathrm{C}\right), 148.3\left(\mathrm{C}_{\mathrm{A} 4}, \mathrm{C}\right), 143.2\left(\mathrm{C}_{\mathrm{B} 1}, \mathrm{C}\right), 139.9$ $\left(\mathrm{C}_{\mathrm{C} 1}, \mathrm{C}\right), 137.3\left(\mathrm{OCH}_{2} \underline{\mathrm{Ph}}\right), 131.8\left(\mathrm{C}_{\mathrm{A} 1}, \mathrm{C}\right), 128.8\left(\mathrm{C}_{\mathrm{B} 3}-\mathrm{C}_{\mathrm{B} 5}, \mathrm{CH}\right), 128.54\left(\mathrm{C}_{\mathrm{C} 3}-\mathrm{C}_{\mathrm{C} 5}\right.$ and $\left.\mathrm{OCH}_{2} \underline{\mathrm{Ph}}\right)$, $127.8\left(\mathrm{OCH}_{2} \underline{\mathrm{Ph}}\right), 127.4\left(\mathrm{C}_{\mathrm{C} 2}-\mathrm{C}_{\mathrm{C} 6}\right.$ and $\left.\mathrm{OCH}_{2} \underline{\mathrm{Ph}}\right), 126.2\left(\mathrm{C}_{\mathrm{C} 4}, \mathrm{CH}\right), 119.7\left(\mathrm{C}_{\mathrm{A} 6}, \mathrm{CH}\right), 114.9\left(\mathrm{C}_{\mathrm{B} 2}-\right.$ $\left.\mathrm{C}_{\mathrm{B} 6}, \mathrm{CH}\right), 113.3\left(\mathrm{C}_{\mathrm{A} 5}, \mathrm{CH}\right), 112.0\left(\mathrm{C}_{\mathrm{A} 2}, \mathrm{CH}\right), 71.0\left(\mathrm{OCH}_{2} \mathrm{Ph}\right), 56.2\left(\mathrm{C}_{\mathrm{A} 3}-\mathrm{OMe}\right), 55.8\left(\mathrm{C}_{\mathrm{B} 4}-\mathrm{OMe}\right)$, $55.3\left(\mathrm{C}_{\mathrm{Al} 1}-\mathrm{CH}_{2}\right), 53.5\left(\mathrm{C}_{\mathrm{Cl} 1}-\mathrm{CH}_{2} \mathrm{CH}_{2} \mathrm{Ph}\right), 33.5\left(\mathrm{C}_{\mathrm{Cl} 1}-\mathrm{CH}_{2} \underline{\mathrm{CH}}_{2} \mathrm{Ph}\right)$.

ESI-HRMS Calcd for $\left(\mathrm{M}+\mathrm{H}^{+}\right) \mathrm{C}_{30} \mathrm{H}_{32} \mathrm{NO}_{3}$ : 454.2382, found: 454.2389 .

$\mathrm{N}$-Benzyl- $\mathrm{N}$-(3,4-bis(benzyloxy)benzyl)aniline (A3B1C1). Yellow oil. ${ }^{1} \mathrm{H}$ NMR $(400 \mathrm{MHz}$ $\left.\mathrm{CDCl}_{3}\right): 7.48-7.22$ (m, 17H, aromatic), 6.91-6.75 (m, $6 \mathrm{H}$, aromatic), 5.19 (s, $\left.2 \mathrm{H}, \mathrm{OCH}_{2} \mathrm{Ph}\right), 5.12$ $\left(\mathrm{s}, 2 \mathrm{H}, \mathrm{OCH}_{2} \mathrm{Ph}\right), 4.56\left(\mathrm{~s}, 4 \mathrm{H}, \mathrm{C}_{\mathrm{Al}}-\underline{\mathrm{CH}}_{2}\right.$ and $\left.\mathrm{C}_{\mathrm{B} 1}-\underline{\mathrm{CH}}_{2}\right)$. ESI-HRMS Calcd for $\left(\mathrm{M}+\mathrm{H}^{+}\right)$ $\mathrm{C}_{34} \mathrm{H}_{32} \mathrm{NO}_{2}$ : 486.2433, found: 486.2420 .

$\boldsymbol{N}$-(3,4-Bis(benzyloxy)benzyl)- $N$-phenethylaniline (A3B1C2). Yellowish oil. ${ }^{1} \mathrm{H}$ NMR (400 $\left.\mathrm{MHz} \mathrm{CDCl}_{3}\right): 7.47-7.18\left(\mathrm{~m}, 17 \mathrm{H}\right.$, aromatic), 6.88-6.74 (m, $6 \mathrm{H}$, aromatic), $5.16\left(\mathrm{~s}, 2 \mathrm{H}, \mathrm{OCH}_{2} \mathrm{Ph}\right.$ ), $5.10\left(\mathrm{~s}, 2 \mathrm{H}, \mathrm{OCH}_{2} \mathrm{Ph}\right), 4.38\left(\mathrm{~s}, 2 \mathrm{H}, \mathrm{C}_{\mathrm{A1}}-\underline{\mathrm{CH}}_{2}\right), 3.55\left(\mathrm{dd}, 2 \mathrm{H}, J=8.06\right.$ and $\left.7.8, \mathrm{C}_{\mathrm{Cl}}-\underline{\mathrm{CH}}_{2} \mathrm{CH}_{2} \mathrm{Ph}\right)$,

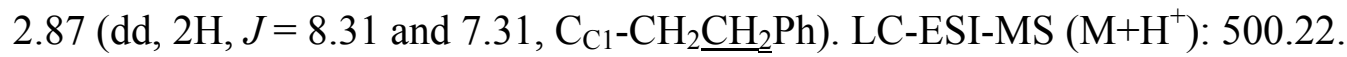

$\mathrm{N}$-Benzyl- $\mathrm{N}$-(3,4-bis(benzyloxy)benzyl)-4-methoxyaniline (A3B2C1). Colorless oil. ${ }^{1} \mathrm{H}$ NMR (300 MHz CDCl $)$ : 7.49-7.25 (m, 15H, aromatic), 6.91-6.70 (m, 7H, aromatic), 5.18 (s, 2H, $\mathrm{C}_{\mathrm{A}^{-}}$ $\left.\mathrm{OCH}_{2} \mathrm{Ph}\right), 5.11\left(\mathrm{~s}, 2 \mathrm{H}, \mathrm{C}_{\mathrm{A} 3}-\mathrm{OCH}_{2} \mathrm{Ph}\right), 4.46\left(\mathrm{~s}, 4 \mathrm{H}, \mathrm{C}_{\mathrm{A} 1}-\underline{\mathrm{CH}}_{2}\right.$ and $\left.\mathrm{C}_{\mathrm{Cl}^{-}-\mathrm{CH}_{2}}\right), 3.78\left(\mathrm{~s}, 3 \mathrm{H}, \mathrm{C}_{\mathrm{B}^{-}}\right.$ OMe). ${ }^{13} \mathrm{C}$ NMR $(75 \mathrm{MHz} \mathrm{CDCl} 3): 151.8\left(\mathrm{C}_{\mathrm{B} 4}, \mathrm{C}\right), 149.0\left(\mathrm{C}_{\mathrm{A} 3}, \mathrm{C}\right), 147.8\left(\mathrm{C}_{\mathrm{A} 4}, \mathrm{C}\right), 143.9\left(\mathrm{C}_{\mathrm{A} 1}\right.$, C), $137.5\left(\mathrm{C}_{\mathrm{C} 1}, \mathrm{C}\right), 137.4\left(\mathrm{C}_{\mathrm{B} 1}, \mathrm{C}\right), 132.3\left(\mathrm{OCH}_{2} \underline{\mathrm{Ph}}\right), 128.5\left(\mathrm{OCH}_{2} \underline{\mathrm{Ph}}\right), 128.5\left(\mathrm{C}_{\mathrm{B} 3}-\mathrm{C}_{\mathrm{B} 5}, \mathrm{CH}\right)$, $127.8\left(\mathrm{OCH}_{2} \underline{\mathrm{Ph}}\right), 127.8\left(\mathrm{OCH}_{2} \underline{\mathrm{Ph}}\right), 127.4\left(\mathrm{OCH}_{2} \underline{\mathrm{Ph}}\right), 127.3\left(\mathrm{C}_{\mathrm{C}^{2}}-\mathrm{C}_{\mathrm{C} 6}, \mathrm{CH}\right), 127.0\left(\mathrm{C}_{\mathrm{A}^{-}}\right.$ $\left.\mathrm{OCH}_{2} \underline{\mathrm{Ph}}\right), 126.8\left(\mathrm{C}_{\mathrm{C} 4}, \mathrm{CH}\right), 119.9\left(\mathrm{C}_{\mathrm{A} 6}, \mathrm{CH}\right), 115.2\left(\mathrm{C}_{\mathrm{B} 2}-\mathrm{C}_{\mathrm{B} 6}, \mathrm{CH}\right), 114.8\left(\mathrm{C}_{\mathrm{B} 3}-\mathrm{C}_{\mathrm{B} 5}, \mathrm{CH}\right), 114.7$ $\left(\mathrm{C}_{\mathrm{A} 2}, \mathrm{CH}\right), 114.0\left(\mathrm{C}_{\mathrm{A} 5}, \mathrm{CH}\right), 71.5\left(\mathrm{C}_{\mathrm{A} 4}-\underline{\mathrm{OCH}}_{2} \mathrm{Ph}\right), 71.2\left(\mathrm{C}_{\mathrm{A} 3}-\mathrm{OCH}_{2} \mathrm{Ph}\right), 55.7\left(\mathrm{C}_{\mathrm{B} 4}-\mathrm{OMe}\right), 55.0$ $\left(\mathrm{C}_{\mathrm{A1}}-\underline{\mathrm{CH}}_{2}\right)$, $54.8\left(\mathrm{C}_{\mathrm{A} 3}-\underline{\mathrm{CH}}_{2}\right)$. ESI-HRMS Calcd for $\left(\mathrm{M}+\mathrm{H}^{+}\right) \mathrm{C}_{35} \mathrm{H}_{34} \mathrm{NO}_{3}$ : 516.2533, found: 516.2519 .

$\mathrm{N}$-(3,4-Bis(benzyloxy)benzyl)-4-methoxy- $\mathrm{N}$-phenethylaniline (A3B2C2). Yellow oil. ${ }^{1} \mathrm{H}$ NMR (400 MHz $\left.\mathrm{CDCl}_{3}\right): 7.57-7.26(\mathrm{~m}, 15 \mathrm{H}$, aromatic), 6.97-6.84 (m, 7H, aromatic), $5.24(\mathrm{~s}$, $\left.2 \mathrm{H}, \mathrm{C}_{\mathrm{A} 3}-\mathrm{OCH} 2 \mathrm{Ph}\right), 5.20\left(\mathrm{~s}, 2 \mathrm{H}, \mathrm{C}_{\mathrm{A} 4}-\mathrm{OCH}_{2} \mathrm{Ph}\right), 4.41\left(\mathrm{~s}, 2 \mathrm{H}, \mathrm{C}_{\mathrm{A} 1}-\underline{\mathrm{CH}}_{2}\right), 3.87\left(\mathrm{~s}, 3 \mathrm{H}, \mathrm{C}_{\mathrm{B} 4}-\mathrm{OMe}\right)$, $3.59\left(\mathrm{dd}, 2 \mathrm{H}, J=7.80\right.$ and $\left.7.81, \mathrm{C}_{\mathrm{C} 1}-\mathrm{CH}_{2} \mathrm{CH}_{2} \mathrm{Ph}\right), 2.95\left(\mathrm{dd}, 2 \mathrm{H}, J=8.06\right.$ and $7.05, \mathrm{C}_{\mathrm{Cl}^{-}}$ $\left.\mathrm{CH}_{2} \mathrm{CH}_{2} \mathrm{Ph}\right)$.

${ }^{13} \mathrm{C}$ NMR (75 MHz CDCl 3 ): $151.9\left(\mathrm{C}_{\mathrm{B} 4}, \mathrm{C}\right), 149.2\left(\mathrm{C}_{\mathrm{A} 3}, \mathrm{C}\right), 148.0\left(\mathrm{C}_{\mathrm{A} 4}, \mathrm{C}\right), 143.2\left(\mathrm{C}_{\mathrm{B} 1}, \mathrm{C}\right), 139.9$ $\left(\mathrm{C}_{\mathrm{C} 1}, \mathrm{C}\right), 137.6\left(\mathrm{OCH}_{2} \underline{\mathrm{Ph}}\right), 137.5\left(\mathrm{OCH}_{2} \underline{\mathrm{Ph}}\right), 132.7\left(\mathrm{C}_{\mathrm{A} 1}, \mathrm{C}\right), 128.9\left(\mathrm{C}_{\mathrm{C} 2}-\mathrm{C}_{\mathrm{C} 6}, \mathrm{CH}\right), 128.5$ $\left(\mathrm{OCH}_{2} \underline{\mathrm{Ph}}\right), 127.8\left(\mathrm{OCH}_{2} \underline{\mathrm{Ph}}\right), 127.4\left(\mathrm{OCH}_{2} \underline{\mathrm{Ph}}\right), 126.3\left(\mathrm{C}_{\mathrm{C} 3}-\mathrm{C}_{\mathrm{C} 5}, \mathrm{CH}\right), 120.0\left(\mathrm{C}_{\mathrm{A} 5}, \mathrm{CH}\right), 119.9$ $\left(\mathrm{C}_{\mathrm{A} 6}, \mathrm{CH}\right), 115.4\left(\mathrm{C}_{\mathrm{B} 3}-\mathrm{C}_{\mathrm{B} 5}, \mathrm{CH}\right), 115.0\left(\mathrm{C}_{\mathrm{B} 2}-\mathrm{C}_{\mathrm{B} 6}, \mathrm{CH}\right), 114.2\left(\mathrm{C}_{\mathrm{A} 2}, \mathrm{CH}\right), 71.6\left(\mathrm{C}_{\mathrm{A} 3}-\mathrm{OCH}_{2}-\mathrm{Ph}\right)$,

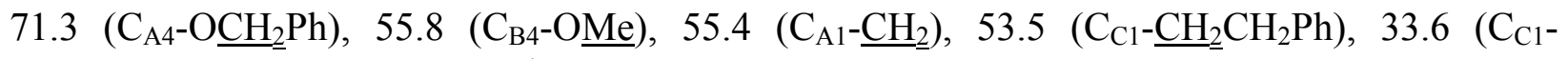
$\left.\mathrm{CH}_{2} \mathrm{CH}_{2} \mathrm{Ph}\right)$. LC-ESI-MS $\left(\mathrm{M}+\mathrm{H}^{+}\right): 530.16$.

\section{In vitro antileishmanial and antimalarial assays}

Antileishmanial activity of the compounds was tested in vitro on a culture of Leishmania donovani promastigotes (Strain S1). In a 96 well microplate assay the compounds with 
appropriate dilution were added to the promastigotes culture $\left(2 \times 10^{6}\right.$ cell $\left./ \mathrm{mL}\right)$ to get the final concentrations of 40,8 and $1.6 \mu \mathrm{g} / \mathrm{ml}$. The plates were incubated at $26 \mathrm{C}$ for 72 hours and growth was determined by Alamar blue assay. ${ }^{22}$ Pentamidine and Amphotericin B were used as the standard antileishmanial agents. All the analogs were simultaneously tested for cytotoxicty on VERO (monkey kidney fibroblast) cells by Neutral Red assay. ${ }^{23} \mathrm{IC}_{50}$ value for each compound was computed from the growth inhibition curve. Antimalarial activity was determined in vitro on chloroquine sensitive (D6, Sierra Leone) and resistant (W2, IndoChina) strains of Plasmodium falciparum. The 96 well microplate assay is based on evaluation of the effect of the compounds on growth of asynchronous cultures of $P$. falciparum, determined by the assay of parasite lactate dehydrogenase (pLDH) activity. ${ }^{24}$ The appropriate dilutions of the compounds were prepared in DMSO or RPMI-1640 medium and added to the cultures of P. falciparum (2\% hematocrit, $2 \%$ parasitemia) set up in clear flat bottomed 96 well plates. The plates were placed into the humidified chamber and flushed with a gas mixture of $90 \% \mathrm{~N}_{2}, 5 \% \mathrm{CO}_{2} \& 5 \% \mathrm{O}_{2}$. The cultures were incubated at $37 \mathrm{C}$ for 48 hours. Growth of the parasite in each well was determined by pLDH assay using Malstat ${ }^{\circ}$ reagent. The medium and RBC controls were also set-up in each plates. The standard antimalarial agents, chloroquine and artemisinin, were used as the positive controls while DMSO was tested as the negative control.

\section{Acknowledgements}

Financial supports through CONICET (Consejo Nacional de Investigaciones Científicas y Técnicas, PIP 2009-0796) is gratefully acknowledged. We thank John Trott for antimalarial \& cytotoxicity assays and Rajnish Sahu for antileishmanial assays. NCNPR, University of Mississippi is partially supported through a cooperative scientific agreement No. 58-6408-20009 from USDA Agricultural Research Service. This investigation received financial support from the UNICEF /UNDP /WORLD BANK /WHO Special Programme for Research and Training in Tropical Diseases (TDR) to GRL.

\section{References}

1. Croft, S. L.; Yardley, V. Cur. Pharm. Design 2002, 8, 319.

2. TDR Annual report 2009. http://apps.who.int/tdr/svc/publications/about-tdr/annualreports/bl10-annual-report

3. Sundar, S.; Rai, M. Curr. Op. Inf. Dis. 2002, 15, 593.

4. Lira, R.; Sundar, S.; Makharia, A.; Kenney, R.; Gam, A.; Saraiva, E.; Sacks, D. J. Infect. Dis. 1999, 42, 1076.

5. Murray, H. W. Antimicrob. Agents Chemother. 2001, 45, 2185. 
6. http://www.who.int/tdr/publications/tdrnews/news68/default.htm TDR NEWS no 69, November 2002.

7. Berman, J. J. .Expert Opin. Drug Metab. Toxicol. 2008, 4, 1209.

8. Sundar, S.; Jha, T. K.; Thakur, C. P.; Sinha, P. K.; Bhattacharya, S. K. New Engl. J. Med. 2007, 356, 2571.

9. Musa, A. M.; Younis, B.; Fadlalla, A.; Royce, C.; Balasegaram, M.; Wasunna, M.; Hailu, A.; Edwards, T.; Omollo, R.; Mudawi, M.; Kokwaro, G.; El-Hassan, A.; Khalil, E. PLoS Negl. Trop. Dis. 2010, 4, e855.

10. For new approaches also see: Davies, C.R.; Kaye, P.; Croft, S.L.; Sundar, S. BMJ. 2003, 15; 326 (7385) 377.

11. (a) Miguel, D. C.; Yokoyama-Yasunaka, J. K. U.; Uliana, S. R. B. PLoS Negl Trop Dis 2008, 2, e249. (b) Miguel, D. C.; Zauli-Nascimento, R. C.; Yokoyama-Yasunaka, J. K.; Katz, S.; Barbieri, C. L.; Uliana, S. R. J. Antimicrob. Chemother. 2009, 63, 365.

12. (a)Tapia, R. A.; Prieto, Y.; Pautet, F.; Domard, M.; Sarciron, M.-E.; Walchshofer, N.; Fillion, H. Eur. J. Org. Chem. 2002, 4005. (b) Salmon-Chemin, L.; Buisine, E.; Yardley, V.; Kohler, S.; Debreu, M.-A.; Landry, V.; Sergheraert, C.; Croft, S. L.; Krauth-Siegel, R. L.; Davioud-Charvet, E. J. Med. Chem. 2001, 44, 548. (c) Sittie, A. A.; Lemmich, E.; Olsen, C. E.; Hviid, L.; Kharazmi, A.; Nkrumah, F. K.; Christensen, S. B. Planta Med. 1999, 65, 259.

13. Martin, M. B.; Grimley, J. S.; Lewis, J. C.; Heath, H. T., III; Bailey, B. N.; Kendrick, H.; Yardley, V.; Caldera, A.; Lira, R.; Urbina, J. A.; Moreno, S. N. J.; Docampo, R.; Croft, S. L.; Oldfield, E. J. Med. Chem. 2001, 44, 909.

14. Labadie, G. R.; Choi, S. R.; Avery, M. A. Bioorg. Med. Chem. Lett. 2004, 14, 615.

15. (a) Clement, B.; Burenheide, A.; Rieckert, W.; Schwarz, J. ChemMedChem 2006, 1, 1260. (b) Bakunova, S. M.; Bakunov, S. A.; Wenzler, T.; Barszcz, T.; Werbovetz, K. A.; Brun, R.; Tidwell, R. R. J. Med. Chem. 2009, 52, 46572. (c) Bakunova, S. M.; Bakunov, S. A.; Patrick, D. A.; Kumar, E. V.; Ohemeng, K. A.; Bridges, A. S.; Wenzler, T. (d) Barszcz, T.; Jones, S. K.; Werbovetz, K. A.; Brun, R.; Tidwell, R. R. J. Med. Chem. 2009, 52, 20163. (e) Bakunov, S. A.; Bakunova, S. M.; Bridges, A. S.; Wenzler, T.; Barszcz, T.; Werbovetz, K. A.; Brun, R.; Tidwell, R. R. J. Med. Chem. 2009, 52, 57634.

16. Werbovetz, K. A.; Brendle, J. J.; Sackett, D. L. Mol. Biochem. Parasitol 1999, 98, 53.

17. (a) George, T. G.; Endeshaw, M. M.; Morgan, R. E.; Mahasenan, K. V.; Delfín, D. A.; Mukherjee, M. S.; Yakovich, A. J.; Fotie, J.; Li, C.; Werbovetz, K. A. Bioorg. Med. Chem. 2007, 15, 6071. (b) George, T. G.; Johnsamuel, J.; Delfín, D. A.; Yakovich, A.; Mukherjee, M.; Phelps, M. A.; Dalton, J. T.; Sackett, D. L.; Kaiser, M.; Brun, R.; Werbovetz, K. A. Bioorg. Med. Chem. 2006, 14, 5699. (c) Bhattacharya, G.; Herman, J.; Delfín, D.; Salem, M. M.; Barszcz, T.; Mollet, M.; Riccio, G.; Brun, R.; Werbovetz, K. A. J. Med. Chem. 2004, 47, 1823.

18. Mu, F.; Coffing, S. L.; Riese Ii, D. J.; Geahlen, R. L.; Verdier-Pinard, P.; Hamel, E.; Johnson, J.; Cushman, M. J. Med. Chem. 2001, 44, 441. 
19. Abdel-Magid, A. F.; Carson, K. G.; Harris, B. D.; Maryanoff, C. A.; Shah, R. D. J Org Chem 1996, 61, 3849.

20. (a) Lidström, P.; Tierney, J.; Wathey, B.; Westman, J. Tetrahedron 2001, 57, 9225. (b) C. Kappe, O.; Dallinger, D.; Murphree, S. S. Practical microwave synthesis for_organic chemists: strategies, instruments, and protocols. Wiley-VCH Verlag: Weinheim, 2009; pp 15-16.

21. (a) Kaidoh, T.; Nath, J.; Fujioka, H.; Okoye, V.; Aikawa, M. Eukaryot. Microbiol. 1995, 42, 61. (b) Dow, G. S.; Armson, A.; Boddy, M. R.; Itenge, T.; McCarthy, D.; Parkin, J. E.; Thompson, R. C. A.; Reynoldson, J. A. Exp. Parasitol. 2002, 100, 155.

22. Mikus, J.; Steverding, D. Parasitol. Int. 2000, 48, 265.

23. Babich, H.; Borenfreund, E. App. Envt. Microbiol., 1991 57, 2101.

24. Makler, M. T.; Ries, J. M.; Williams, J. A.; Bancroft, J. E.; Piper, R. C.; Gibbins, B. L.; Hinriches, D. J. Am. J. Trop. Med. Hyg. 1993 48, 739. 